
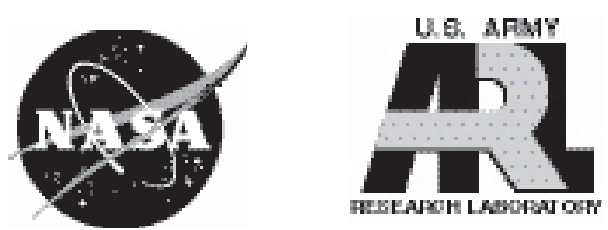

\title{
Pre-Stall Behavior of a Transonic Axial Compressor Stage Via Time-Accurate Numerical Simulation
}

Jen-Ping Chen

The Ohio State University, Columbus, Ohio

Michael D. Hathaway and Gregory P. Herrick

U.S. Army Research Laboratory, Glenn Research Center, Cleveland, Ohio 


\section{NASA STI Program . . . in Profile}

Since its founding, NASA has been dedicated to the advancement of aeronautics and space science. The NASA Scientific and Technical Information (STI) program plays a key part in helping NASA maintain this important role.

The NASA STI Program operates under the auspices of the Agency Chief Information Officer. It collects, organizes, provides for archiving, and disseminates NASA's STI. The NASA STI program provides access to the NASA Aeronautics and Space Database and its public interface, the NASA Technical Reports Server, thus providing one of the largest collections of aeronautical and space science STI in the world. Results are published in both non-NASA channels and by NASA in the NASA STI Report Series, which includes the following report types:

- TECHNICAL PUBLICATION. Reports of completed research or a major significant phase of research that present the results of NASA programs and include extensive data or theoretical analysis. Includes compilations of significant scientific and technical data and information deemed to be of continuing reference value. NASA counterpart of peer-reviewed formal professional papers but has less stringent limitations on manuscript length and extent of graphic presentations.

- TECHNICAL MEMORANDUM. Scientific and technical findings that are preliminary or of specialized interest, e.g., quick release reports, working papers, and bibliographies that contain minimal annotation. Does not contain extensive analysis.

- CONTRACTOR REPORT. Scientific and technical findings by NASA-sponsored contractors and grantees.

- CONFERENCE PUBLICATION. Collected papers from scientific and technical conferences, symposia, seminars, or other meetings sponsored or cosponsored by NASA.

- SPECIAL PUBLICATION. Scientific, technical, or historical information from NASA programs, projects, and missions, often concerned with subjects having substantial public interest.

- TECHNICAL TRANSLATION. Englishlanguage translations of foreign scientific and technical material pertinent to NASA's mission.

Specialized services also include creating custom thesauri, building customized databases, organizing and publishing research results.

For more information about the NASA STI program, see the following:

- Access the NASA STI program home page at http://www.sti.nasa.gov

- E-mail your question via the Internet to help@ sti.nasa.gov

- Fax your question to the NASA STI Help Desk at 301-621-0134

- Telephone the NASA STI Help Desk at 301-621-0390

- Write to: NASA Center for AeroSpace Information (CASI) 7115 Standard Drive Hanover, MD 21076-1320 
NASA/TM-2008-215163
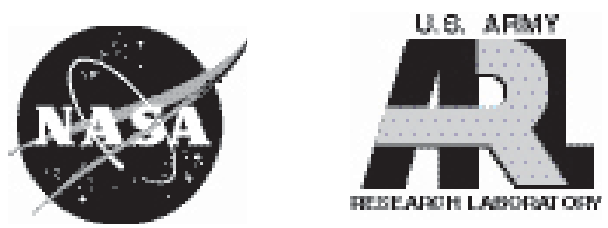

\section{Pre-Stall Behavior of a Transonic Axial Compressor Stage Via Time-Accurate Numerical Simulation}

Jen-Ping Chen

The Ohio State University, Columbus, Ohio

Michael D. Hathaway and Gregory P. Herrick

U.S. Army Research Laboratory, Glenn Research Center, Cleveland, Ohio

Prepared for

Turbo Expo 2007

sponsored by the American Society of Mechanical Engineers

Montreal, Canada, May 14-17, 2007

National Aeronautics and

Space Administration

Glenn Research Center

Cleveland, Ohio 44135 


\section{Acknowledgments}

The authors would like to acknowledge the invaluable discussions and technical advises from Dr. John Adamczyk, Dr. Dale Van Zante, Dr. Gerard Welch, and Dr. Tony Strazisar of NASA Glenn Research Center, and Dr. Choon Tan, Dr. Yifang Gong, and Professor Edward Greitzer of MIT Gas Turbine Laboratory. Thanks to Mr. Sean Barrows, Mr. Trevor Goerig, and Mr. Benjamin Johnson of The Ohio State University for their hard work in preparing the manuscript. The high performance computing resources are provided by DoD Grand Challenge Project. This research was supported by Army Research Office, Project No 43737-EG. Dr. Thomas Doligalski, technical monitor.

Level of Review: This material has been technically reviewed by technical management.

Available from

NASA Center for Aerospace Information 7115 Standard Drive

Hanover, MD 21076-1320
National Technical Information Service 5285 Port Royal Road Springfield, VA 22161 


\title{
Pre-Stall Behavior of a Transonic Axial Compressor Stage Via Time-Accurate Numerical Simulation
}

\author{
Jen-Ping Chen \\ The Ohio State University \\ Columbus, Ohio 43210 \\ Michael D. Hathaway and Gregory P. Herrick \\ U.S. Army Research Laboratory \\ Glenn Research Center \\ Cleveland, Ohio 44135
}

\begin{abstract}
CFD calculations using high-performance parallel computing were conducted to simulate the pre-stall flow of a transonic compressor stage, NASA compressor Stage 35. The simulations were run with a full-annulus grid that models the $3 \mathrm{D}$, viscous, unsteady blade row interaction without the need for an artificial inlet distortion to induce stall. The simulation demonstrates the development of the rotating stall from the growth of instabilities. Pressure-rise performance and pressure traces are compared with published experimental data before the study of flow evolution prior to the rotating stall. Spatial FFT analysis of the flow indicates a rotating long-length disturbance of one rotor circumference, which is followed by a spike-type breakdown. The analysis also links the long-length wave disturbance with the initiation of the spike inception. The spike instabilities occur when the trajectory of the tip clearance flow becomes perpendicular to the axial direction. When approaching stall, the passage shock changes from a single oblique shock to a dual-shock, which distorts the perpendicular trajectory of the tip clearance vortex but shows no evidence of flow separation that may contribute to stall.
\end{abstract}

\section{Introduction}

Advances in gas turbine engine technology have made possible the production of highly efficient engines. However, the useful operating range of a gas turbine engine is limited by the stable operation of the compressor. The limiting instability can be characterized by either stall or surge. Surge is the zeroth order planar oscillation mode resulting from overall imbalance of the entire propulsion system, thus, analysis would have to include full volume and ducting. This violent system instability is always preceded by a rotating stall. Surge and stall can cause destructive damage to engines and should be avoided. Understanding the physical process of the onset of rotating stall can aid the design of better control method to stabilize the system and enhance engine performance.

Understanding stall inception has been an active research effort for the past five decades. The events leading to rotating stall have been traditionally classified according to two different types of wave disturbances moving around the annulus: long-length (modal) and short-length (spike) waves. Longlength wave disturbances are those with length on the order of the rotor circumference. This type of disturbance is caused by the characteristic frequencies of the compression system. Theories to model the long-length instability were developed by Moore (1984), and Moore and Greitzer (1986). The assumption is that the disturbance length scale is much larger than one blade pitch, and that the entire blade row can be modeled, both spatially and temporally, without the knowledge of the detailed flow inside the blade passages. This approach predicts the existence of long-length waves leading to stall. McDougall $(1988,1989)$ demonstrated the existence of the modal waves through experiments, and Garnier et al. (1991) supported the validity of the Moore and Greitzer model with detailed measurements. Unsteady pressure or axial velocity measurements from probes placed around the annulus are usually used to track the development of modal waves. Modal oscillations often have an axial extent from inlet to exit. It is typically a $2 \mathrm{D}(\theta, x)$ phenomenon, which is not an early form of stall cell but instead represents harmonic oscillations of the flow field. It usually appears when the shape of the total-tostatic pressure rise characteristic becomes horizontal.

The second type of stall inception mechanism is the shortlength, or spike disturbances. These are disturbances with length scale on the order of blade passage breadth. Spike can be viewed as embryonic stall cells with flow breakdown in local regions (Camp \& Day, 1998), it is a 3D phenomenon whose development depends on the flow structure within the blade passage. A common scenario for the spike stall inception process is that localized, 3D pockets of instability in multiple blade passages erupt first to form small sized multi-cell rotating stall. These stall cells rotates at 30 to $85 \%$ rotor speed initially and then merge into a single rotating stall cell within a few rotor revolutions (Day, 1993). The final speed of the consolidated stall cell is nearly half or less of the rotor speed (Cumpsty, 2004). A spike disturbance mostly occurs when the slope of the pressure rise characteristic is still negative. That is, the pressure still rises as the mass flow reduces.

The above discussions indicate that the slope of the pressure rise characteristic may correlate with the stall inception type. Spike and mode can also be the different aspects of the stall inception process and can exist in the same machine (Day, 1993). Day indicated that modal waves may be measur- 
able in the machine for as many as 200 rotor revolutions before stall. A spike disturbance, on the other hand, once formed, can lead to rotating stall quickly, usually within a few rotor revolutions.

Numerical simulation using CFD techniques has been shown as an alternative way to analyze aerodynamic problems and is a complement to experiments in the understanding of complex flow phenomena. Flow structure can be examined in detail where experimental measurements are difficult or impossible. During the last ten years steady-flow simulations have provided an increasingly accurate prediction of the flow up to the point of compressor stall. Attempts to study stall through unsteady simulations of a periodic subset of the blades in a compressor blade row (Hoying et al., 1988, Vo et al., 2005, Davis and Yao, 2006) or through reduced-order unsteady flow models (Gong et al. 1999) have reached valuable findings of the flow structure leading to stall. However, since the temporal flow field variations that occur during stall inception are not harmonics of blade passing frequency, a fullannulus model should be used to remove the constraint of the periodic model in order to study the transition from a steady flow into the unsteady stalling flow, and to resolve flow features of length scale on the order of the rotor circumference. Such simulations have been done two-dimensionally ( He, 1997, Saxer-Felici et al., 2000), but stall and the instabilities leading to stall are inherently three-dimensional phenomena. Predicting stall phenomena may thus require threedimensional unsteady full-annulus simulations, which is a daunting computational endeavor requiring considerable computational resources. Due to the rapid advance of high performance computing in the past decade, advanced CFD codes have benefited from the almost unlimited computing potential of parallel computing. Recently, Chen et al. (2006) demonstrated the ability to conduct a full-annulus 3D unsteady computation of an entire compressor stage while Hah et al. (2006) also conducted a full-annulus 3D computation of an isolated rotor. This trend indicates that large-scale simulation using parallel computing is within reach.

Previous comparisons of the time-averages of unsteady phase-lag and partial annulus predictions to measurements have shown the validity of the TURBO code to capture the $1 \mathrm{D}$, and 2D characteristics of this compressor (Hathaway et al., 2004). The intent of this work is to use the available experimental data to provide assessment of the code and to show evidence that the computational model reasonably captures the inherent behavior of compressors as they are throttled into stall. It is recognized that some features of the actual tested compressor are not captured by the computational model, for example the leakage gap at the rotor/stator hub interface, the actual blade tip profile, and the geometry of the upstream and downstream ducting between the plenum and throttle valve locations. Although these features might influence the actual compressor stall, they are not considered requisite to the understanding of the fundamental stall inception characteristics.

\section{Axial Compressor, Stage 35}

NASA research single-stage compressor Stage 35, representative of the advanced transonic core compressor, is used in this investigation. A schematic of the compressor test rig and compressor geometry is provided in figure 1 and the design parameters are provided in Table 1 . Stage 35 produces 1.8 total pressure ratio at a mass flow rate of $20.2 \mathrm{~kg} / \mathrm{sec}$ at the design speed of $17189 \mathrm{rpm}$. Details of the Stage 35 geometry, operating conditions, and the experimental results are provided by Reid and Moore (1978).

TABLE 1.-DESIGN PARAMETERS OF STAGE 35

\begin{tabular}{|c|}
\hline Rotor rpm at $100 \%$ Speed.. \\
\hline Tip Speed $(\mathrm{m} / \mathrm{s})$. \\
\hline Hub/Tip Radius .. \\
\hline Rotor Aspect Ratio. \\
\hline 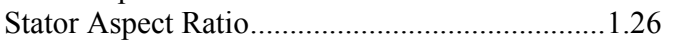 \\
\hline Number of Rotor Blades...... \\
\hline 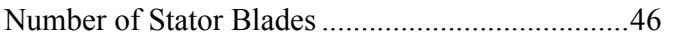 \\
\hline
\end{tabular}
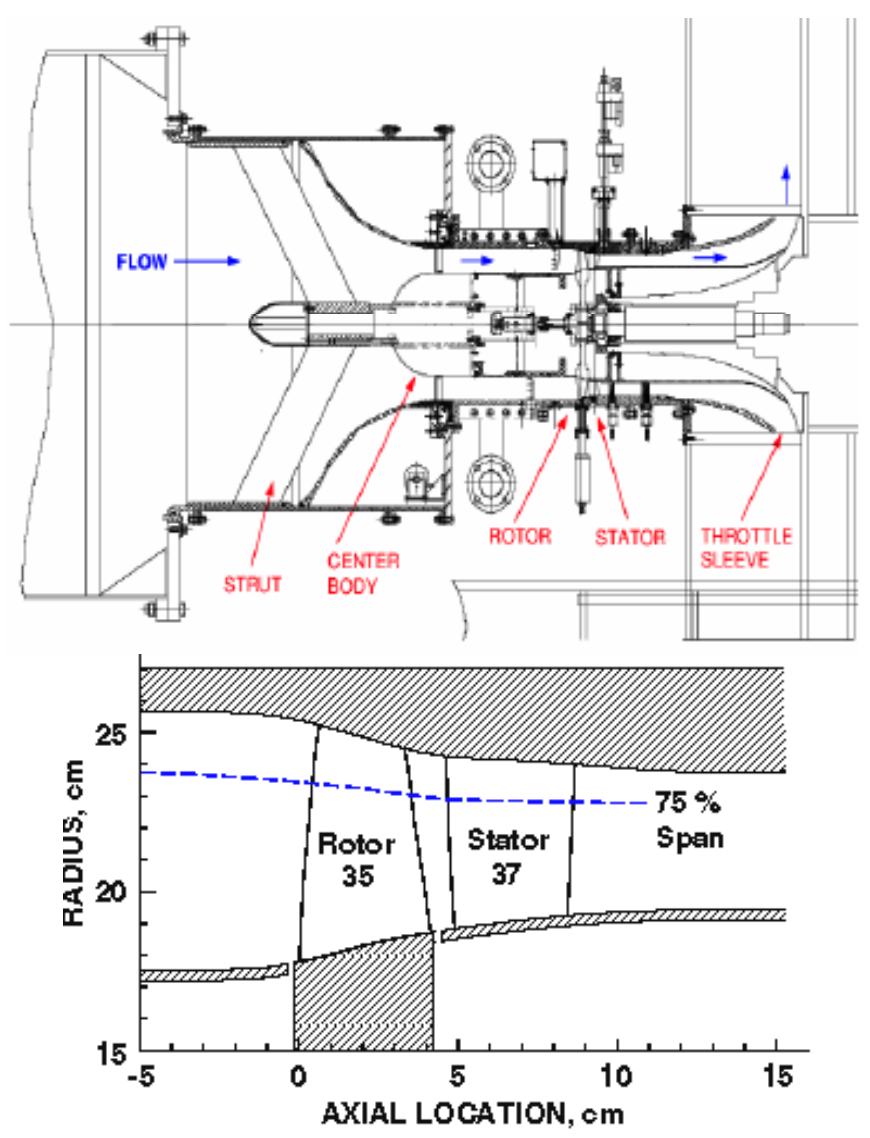

Figure 1.-NASA high-speed compressor Stage 35. 


\section{Relevant Experimental Work}

Time-resolved pressure measurement of Stage 35 near stall was reported by Bright et al. (1999). The experiment was performed at $85 \%$ design speed. Several configurations, including a clean-inlet case, were reported in that paper. For the interest of this study we will focus on the clean-inlet case. The compressor was transitioned into stall using a continuous throttle maneuver. Time-resolved pressure was recorded by high-frequency-response transducers at eight locations equally spaced around the annulus. Figure 2 reproduces the pressure traces of the clean-inlet case for 180 revolutions prior to stall reported in that paper (the original data is not available to us). Based on the pressure disturbance, Bright et al. commented that the compressor with the clean inlet stalls due to modal instabilities, and at 40 revolutions before stall there appear to be spikes on top of the modal wave. They concluded that "This indicates that our high-speed stage under normal stalling condition is considered a 'modal' machine, since modal instabilities dominate the pre-stall behavior with some added pip instabilities present just before stall."

In the following we take a closer look at this experimental data. The shapes of the modal disturbances indicated in figure 2 resemble sinusoidal waves with a temporal period of 10 rotor revolutions. The speed of the modal disturbances, as indicated by the slope of line $\mathrm{A}$, connecting the peaks of the pressure wave, is zero. This indicates the modal disturbance is caused by axisymmetric longitudinal system disturbances. The system includes all ducting and volumes of the experimental facility. This modal disturbance is the surge mode that oscillates at a frequency of $10 \%$ rotor speed - equivalent to the 10 rotor revolutions period it covers. Unlike a typical rotating modal wave, the surge mode does not rotate. The surge mode is a compression system wide resonance that cannot be modeled with the current simulation, because the computational grid does not include the ducting of the test facility, which is quite substantial, as shown in figure 1. The surge mode oscillates over 10 rotor revolutions and is characterized by a length scale of 10 rotor circumferences, or, more than one rotor circumference.

As the compressor throttles closer to stall at about 10 revolutions before stall, there is a secondary disturbance, much like a spike in the time scale of figure 2. Looking more closely, this secondary disturbance covers a circumferential distance of one rotor circumference, as indicated in the enlarged image. It sits on top of the surge mode and rotates around the annulus at about $80 \%$ rotor speed, indicated by line B. Because the length scale of this disturbance is the entire annulus, which is much larger than that of a typical spike, it is classified as a mode. For discussions in the rest of the paper, this rotating longlength disturbance is also referred to as a rotating modal disturbance. This long-length disturbance is followed by the eventual flow breakdown. Due to the picture quality, we are unable to discern the transition between the start of the rotating long-length disturbance and the final breakdown. The long-length disturbance has a length scale of one rotor
Pressure Traces for No Control, No Blowing Stage 35

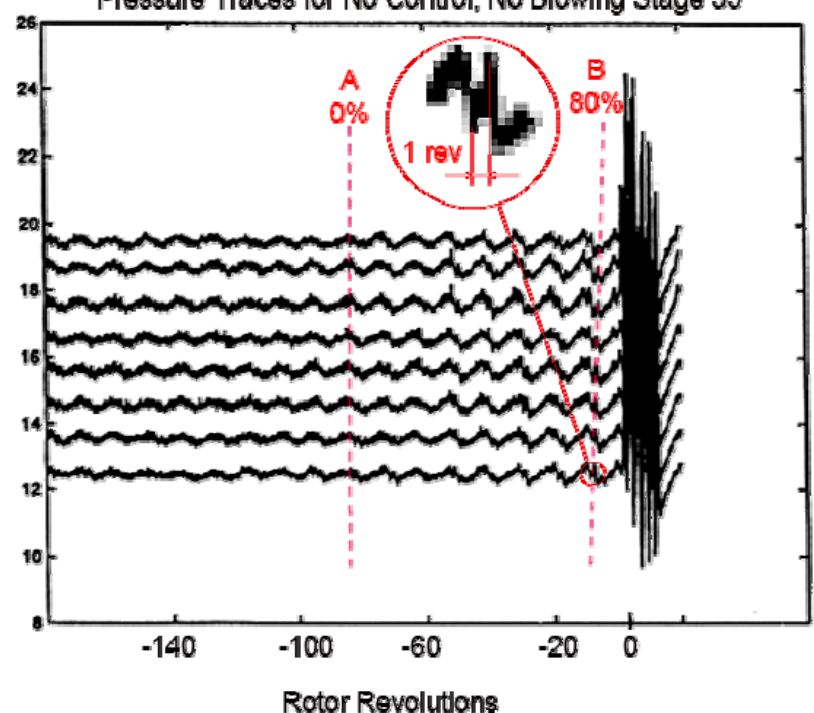

Figure 2.-Experiment pressure traces for clean inlet, $85 \%$ design speed, Stage 35, Michelle Bright et al. (1999).

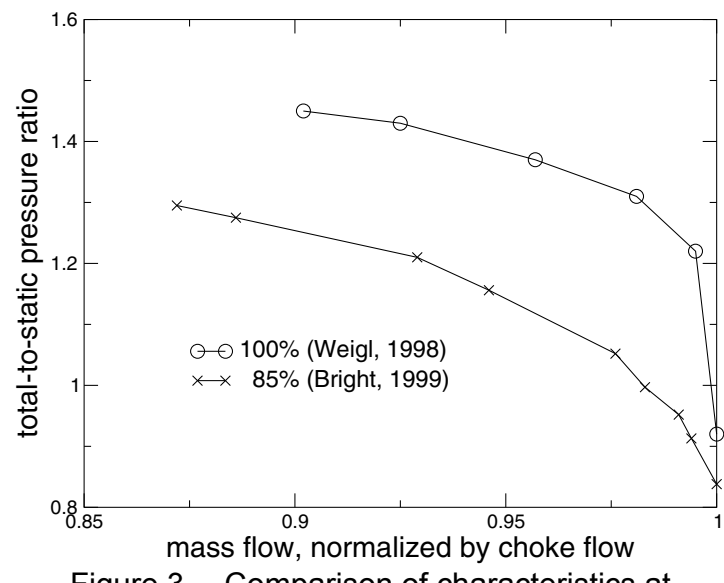

Figure 3.-Comparison of characteristics at 85 and $100 \%$ speed, Stage 35.

circumference, or, less than one rotor circumference. This is in contrast to the more than one rotor circumference of the surgemode. The rotating long-length disturbance, because of its length scale, can only be resolved by a full annulus simulation.

The simulation reported in this work is part of an overall leffort to examine steady tip injection stall flow control for Stage 35 at design speed with the clean inlet. As such, the simulation was conducted at design speed. To our knowledge, there is no pressure trace data available at design speed as that shown in figure 2 . Therefore, we will use the $85 \%$ speed case to compare with the simulated results. While the speeds are different, the two cases are both transonic compressors and share common features as we explore the flow behavior prior to stall. The experimental characteristics at 85 and $100 \%$ speed are compared in figure 3 . Both case stalls at the peak of static pressure rise. More importantly, their slopes near stall are similar. These similarities justify the use of $85 \%$ speed for comparison. 


\section{Numerical Methodology}

TURBO is a physics-based simulation tool for multistage turbomachinery. The solver computes the fluid conservation laws without ad hoc modeling of any flow phenomena other than models required for turbulence. This code solves the unsteady Reynolds-averaged Navier-Stokes equations and a decoupled $k-\varepsilon$ turbulence model. The code is implemented in a portable, scalable form for distributed-memory parallel computers using MPI message passing. The parallel implementation employs domain decomposition and supports general multi-block grids with arbitrary grid-block connectivity. The solution algorithm is a Newton iterative implicit time-accurate scheme with characteristics-based finite-volume spatial discretization. The Newton subiterations are solved using a concurrent block-Jacobi symmetric Gauss-Seidel (BJ-SGS) relaxation scheme. Because all of the fundamental fluid mechanics are computed, the code is capable of capturing the nonlinear characteristics of the flow fields of interest. With the actual modeling of blade rows in relative motion, this code is capable of computing the unsteady interactions between blade rows. Details of the flow solver can be found in Chen and Whitfield (1993). The approach to parallelization for largescale, complex problems is discussed in Chen and Briley (2001). In the following we discuss several issues applied to the code in the simulation of rotating stall.

\section{Full Compressor Stage Simulation}

The intent to simulate the inception and maturation of longwavelength circumferential modes, with wave numbers as low as unity, requires full annulus simulations. A time-accurate sliding interface (Chen and Barter, 1998) is implemented, in which pressure waves in all directions (axial, radial, and circumferential) are passed unaltered between the rotor and the stator. This attribute is necessary to examine the temporal and spatial responses associated with blade row interaction during stall inception.

\section{Inlet Boundary Condition}

An isentropic inlet condition (Chen and Whitfield, 1993) is applied, where the span-wise total condition is prescribed. This boundary condition preserves the upstream total conditions at test facility level, but can potentially reflect out-going pressure waves back to the computational domain.

\section{Exit Boundary Condition}

The traditional choice of exit boundary for stable flow is the radial equilibrium condition. This boundary condition uses a preset exit static pressure. In near-stall or during-stall conditions, compressor pressure rise drops and a preset exit pressure cannot match the pressure drop. In this study we relieve the situation by the use of a "choked" throttle model that specifies corrected mass flow at the exit. This boundary condition al- lows variation of exit static pressure to match the compressor exit mass corrected to the exit total condition.

\section{Tip Clearance Model}

The tip gap was modeled by the tip clearance model of Kirtley (1990). This model ensures the conservation of mass and momentum through the tip gap without the need of a tip clearance grid. A gridding strategy suggested by VanZante et al. (2000) is adopted in this study where 10 points are placed in the tip gap region. Although the detailed physics of the development of the leakage vortex are not captured the tip clearance model was considered adequate for predicting the first order effects of the leakage vortex strength, extent, and direction (Chima, 1998).

\section{Gridding}

This compressor stage consists of 36 rotor blades and 46 stator blades. For the purpose of conducting simulations with tip injectors in another effort, we built a three-blade-row grid as shown in figure 4 . The injector row has twelve injectors (not activated in this study) that are equally spaced in the circumferential direction. The grid size of the rotor is $151(\mathrm{x})$, $71(\mathrm{r})$, and $56(\theta)$ with $81(\mathrm{x})$ and $61(\mathrm{r})$ points on the blade. The grid size of the stator is $141(\mathrm{x}), 71(\mathrm{r})$, and $79(\theta)$ with $81(\mathrm{x})$ and 53(r) points on the blade. The rotor tip clearance is $1 \%$ of

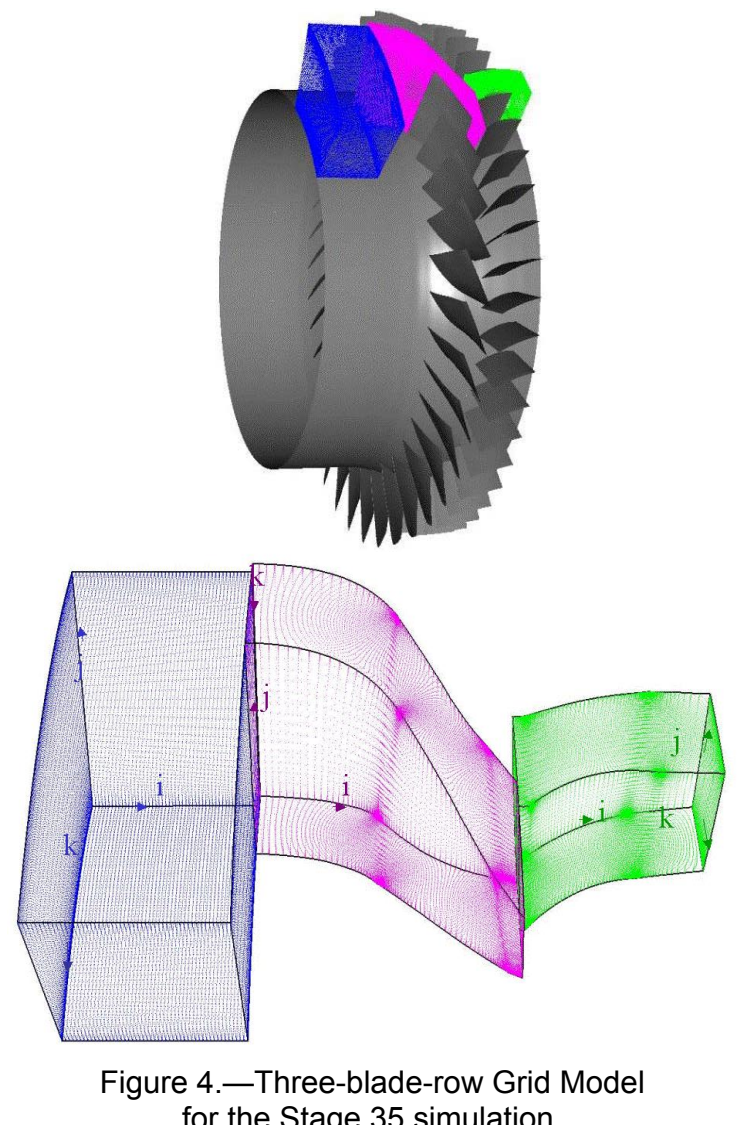

for the Stage 35 simulation. 
rotor tip chord. The grids are replicated around the annulus to generate a full-annulus grid with a total of 67 million grid points. The grid is then partitioned into 328 blocks. The simulations were run on an IBM P4 cluster at NAVO MSRC using 328 CPUs with $24 \mathrm{hr}$ (wall clock) computation time for one rotor revolution. In the simulation of the development of rotating stall, 10 revolutions were needed. Ideally, each operating point should be run at least 10 revolutions to ensure convergence, especially for points close to stall. The time for each speedline would then be 0.5 millions CPU-hours ( 6 operating points).

Constrained by the computational resources for the full annulus simulations, very short upstream and downstream computational domains were used here. This choice prompts two caveats: 1) The exclusion of the test facility volume effect prevents the modeling of the surge mode. Any modal activity shows up in the simulation should be a result of the compound effect of the blades (both rotor and stator if the interaction of the two matters) and the limited volume effect present in the ducting of the current grid. 2) Limiting the axial extent of the computational domain can potentially disrupt long length modes due to the reflective inlet boundary. Because pressure waves (with length $\lambda$ ) decay $e^{-L / \lambda}$ through a distance $L$, the common practice is to locate inlet boundary at least one rotor circumference away from the rotor so that pressure wave of one rotor circumference decays sufficiently before reaching the inlet. Typically, the modal instability shows up hundreds of revolutions prior to stall. Complete simulation of the evolution of such modal instability is beyond the computational resources available in this study. Our intent, therefore, is to examine the development of the modal disturbances as they first emerge before reaching the inlet, rather than the complete resolution of the modal stall process. In this aspect, a shorter upstream domain is justified.

\section{Results and Discussions}

The difference of the throttling processes in the simulation and the experiment is that in the simulation the exit boundary condition is changed in discrete steps, while in the experiment the compressor transitioned to stall through a continuous throttling maneuver. In this simulation, a new throttle setting restarts from the solution of a previous throttle setting. Due to computational resources, each throttle setting was only run for a few revolutions before moving to the next. Generally, it was sufficient to reach convergence within 4 revolutions while away from stall. As stall was approached, more (6 or more) revolutions were required to assure convergence.

\section{Stage Characteristics}

The computed and experimental characteristics (speedlines) are shown in figure 5. The data used in this figure is the ratio of exit static pressure to inlet total pressure versus mass rate corrected to inlet total condition. The computed speedline is generated by incrementally closing the throttle setting (decreasing exit corrected mass flow) from A to $\mathrm{F}$. The overall shape of the computed characteristic is similar to the experimental data, so is the slope of the characteristic near the peak pressure (throttle point D). Since the slope of the compressor characteristic correlates with the type of stall inception, we consider the simulation reasonable to capture the stall inception mechanisms.

Point D in figure 5 is the last stable throttle setting. Points E and $\mathrm{F}$ both restart from Point $\mathrm{D}$ and develop into rotating stall. In both cases the exit pressure changes from the peak at $D$ into a transitional peak and then drops to a much lower level during rotating stall, as shown in figure 6(a). This demonstrates the throttling effect of the corrected mass exit boundary condition by allowing the exit pressure to vary as the flow condition changes. The pressure ratios shown in figure 5 for $\mathrm{E}$ and $\mathrm{F}$ are the transitional peak pressures before entering rotating stall. Point $\mathrm{D}^{*}$ is the approximate stall point from the experiment. The actual simulated stall point should occur between D and E. The actual stall point depends on many issues, such as tip clearance height, deviation of real blade geometry from designed geometry, as well as the type of turbulence modeling in the numerical simulation. These details may not be correctly represented in this simulation. Even though the exact stall point is important, for the intent of this paper the simulation is considered adequate to examine the general physical trends leading to stall.

In the following sections, we first present the entire evolution of the rotating stall as the throttle setting changes from D to $\mathrm{F}$. This is then followed by a closer examination of the prestall flow development from $\mathrm{D}$ to $\mathrm{E}$, with $\mathrm{E}$ being closer to the stable point $\mathrm{D}$.

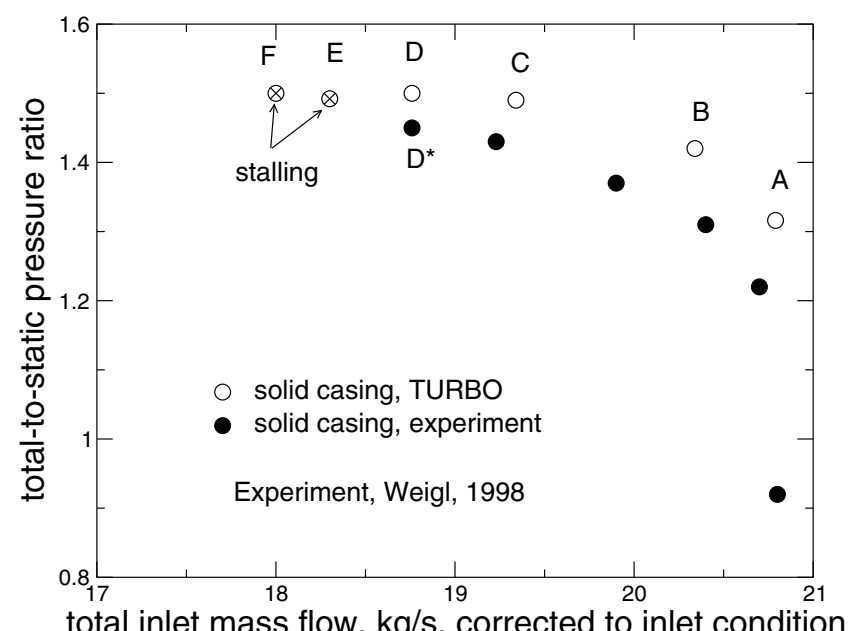

Figure 5.-Stage 35 computed and measured speedline, design speed. 


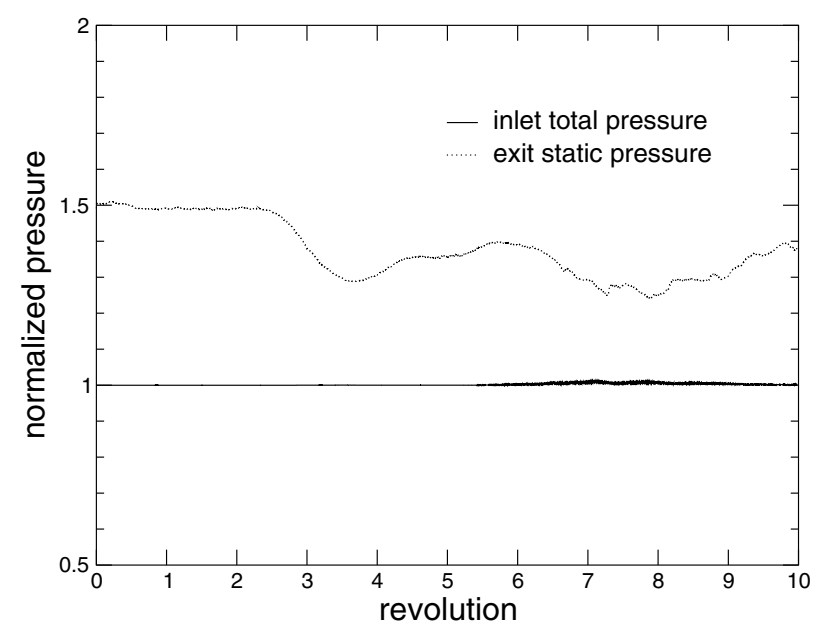

(a) Pressure

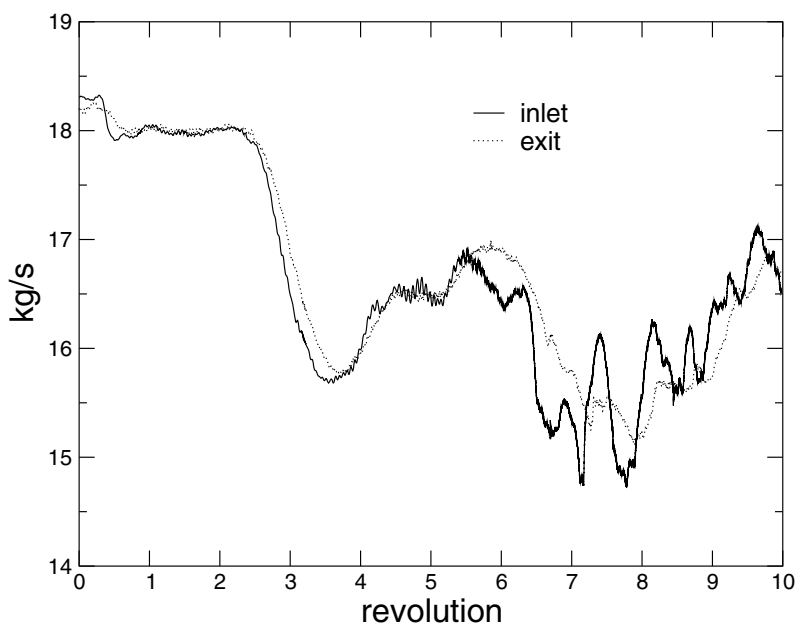

(b) Mass flow

Figure 6.-Pressure and mass variation during rotating stall at throttle setting $\mathrm{F}$.

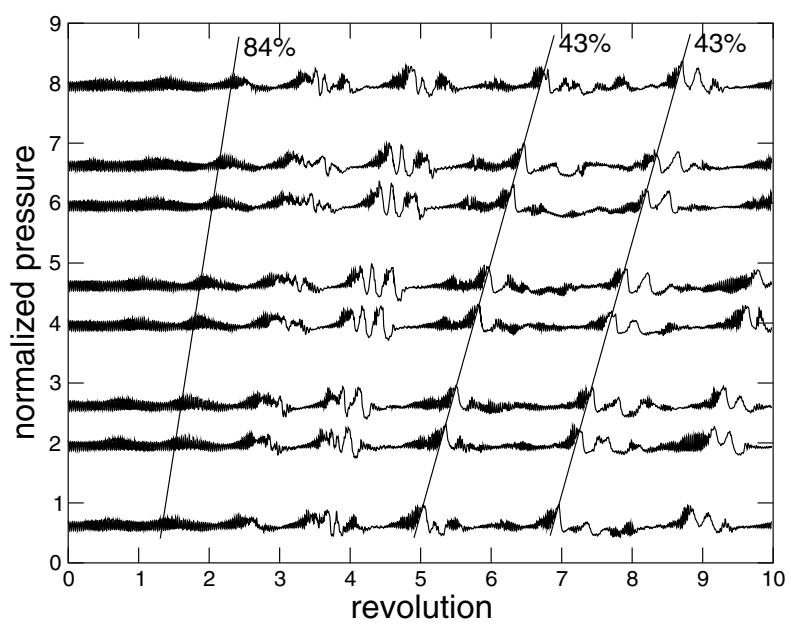

Figure 7.-Time history of static pressure variation at 8 locations around the annulus located $44 \%$ chord ahead of the rotor of Stage 35, throttling setting $F$.

\section{Evolution of the Rotating Stall}

This result was reported in Chen et al. (2006) and is outlined here for completeness. The rotating stall was captured by the time variation of static pressure at eight pressure transducers circumferentially spaced upstream of the rotor. The probes are located $44 \%$ chord upstream of the rotor leading edge at $98 \%$ span. The circumferential locations are $10^{\circ}, 70^{\circ}, 100^{\circ}$, $160^{\circ}, 190^{\circ}, 250^{\circ}, 280^{\circ}$, and $340^{\circ}$. The history of pressure variations are shown in figure 7 , in which the pressure levels are offset by the probe circumferential locations. Because the volume effect is not modeled in the simulation, the pressure disturbance of figure 7 should be viewed as a filtered version of figure 2 by removing the surge mode oscillations.

Small, periodic pressure variations caused by the rotor blade passing, as indicated by the thickness of the curves, are present in all curves of figure 7. A smooth disturbance is visible at $\mathrm{t}=0.7 \mathrm{~T}(\mathrm{~T}=$ time for one rotor revolution) traveling at full rotor speed. This disturbance, analyzed in further detail later, has a length scale of one rotor circumference, thus is classified as a modal disturbance. The rotating modal disturbance continues to grow in magnitude but the speed slows to $84 \%$ rotor speed in approximately one revolution. After $2 \mathrm{~T}$, it transforms into several spike disturbances around the annulus, each with a smaller length scale of a few blade passages. The spike disturbances then grew in magnitude and slowed down to $43 \%$ in 4 revolutions. Inlet and exit mass flow histories during the same period are shown in figure 6(b), in which the mass flow remained relatively flat in the first two revolutions at $18 \mathrm{~kg} / \mathrm{s}$ before it dropped sharply and underwent large variations of $14 \%$ of the peak mass flow.

In figures 8 and 9 , the entropy on a surface of revolution near the casing is shown at two instants in time. The fullannulus surface is illustrated by two half-annulus surfaces. At $\mathrm{t}=3.8 \mathrm{~T}$, figure 8 , the early phase of the stall inception, three separate high entropy (red color) regions can be seen, with the axial extent covering from one chord upstream to aft of the stator leading edges. The radial extent of the stall cell is shown in the axial cut-plane at $16 \%$ chord before the rotor. Again, the high entropy region shows the stall cell extending about $30 \%$ span from the casing. At $\mathrm{t}=10 \mathrm{~T}$, figure 9 , the stall cell evolves into the final stage as its rotating speed became stabilized. The three-cell stall has merged into a single-cell stall with the axial extent covering all the way from the inlet of the computation domain to aft of the stator trailing edge. The radial extent of the stall cell has now extended about $70 \%$ span from casing.

The evolution of the simulated rotating stall cell is similar to the spike stall inception mechanism commonly observed in that localized, three-dimensional pockets of instability in multiple rotor passages break up to form the initial phase of a rotating stall cell, usually with several small-sized stall cells. These small stall cells move fast at the beginning and then merge into a single rotating stall cell within a few revolutions before slowing down to about half of the rotor speed as the rotating stall becomes fully developed. 

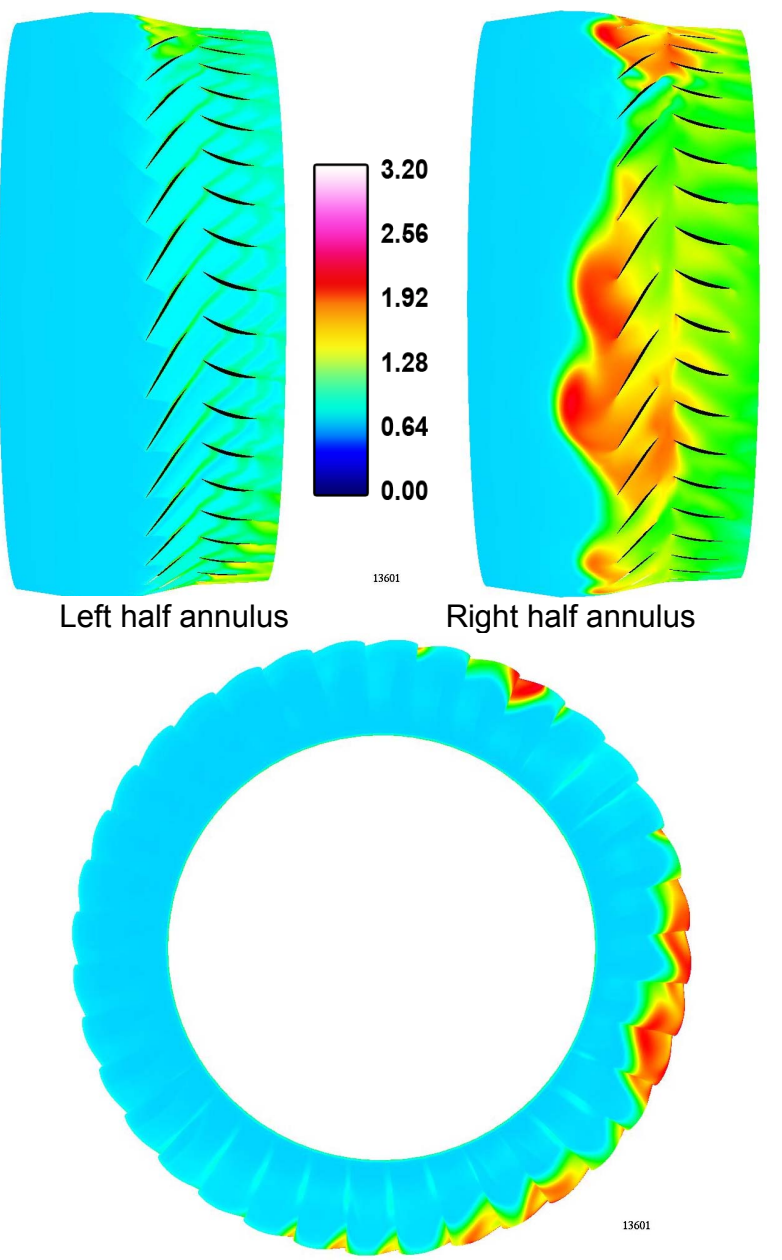

$16 \%$ chord upstream of rotor leading edge

Figure 8.-Entropy of Stage 35 during stall inception process, $\mathrm{t}=3.8 \mathrm{~T}$.

In the previous section we gave a brief description of the overall evolution of the rotating stall using throttle setting $\mathrm{F}$. In the following sections we will examine the process that leads to the initial flow breakdown, i.e., the stall inception process. Restarting from the stable solution of $\mathrm{D}$, the simulation was repeated with throttle setting $\mathrm{E}$, the mass flow history during the transition from $\mathrm{D}$ to $\mathrm{E}$ is shown in figure 10 . The simulation shows that after four revolutions after the restart the mass flow starts to decrease, leading to the rotating stall. Three time stamps marked E1 (1.7T), E2 (3.2T), and E3 (4.3T) will be referenced in the following discussions.

\section{Development of Long-Length Disturbance}

Both experimental (Spakovszky et al., 1999 and Suder et al. 2001) and computational studies (Chen et al., 2006, Davis and Yao et al., 2006) indicate the rotating stall of this compressor initiates in the rotor tip region, so the analysis will focus on the rotor tip. Instantaneous pressure profiles around the annulus near the rotor tip leading edge are shown in figure 11.
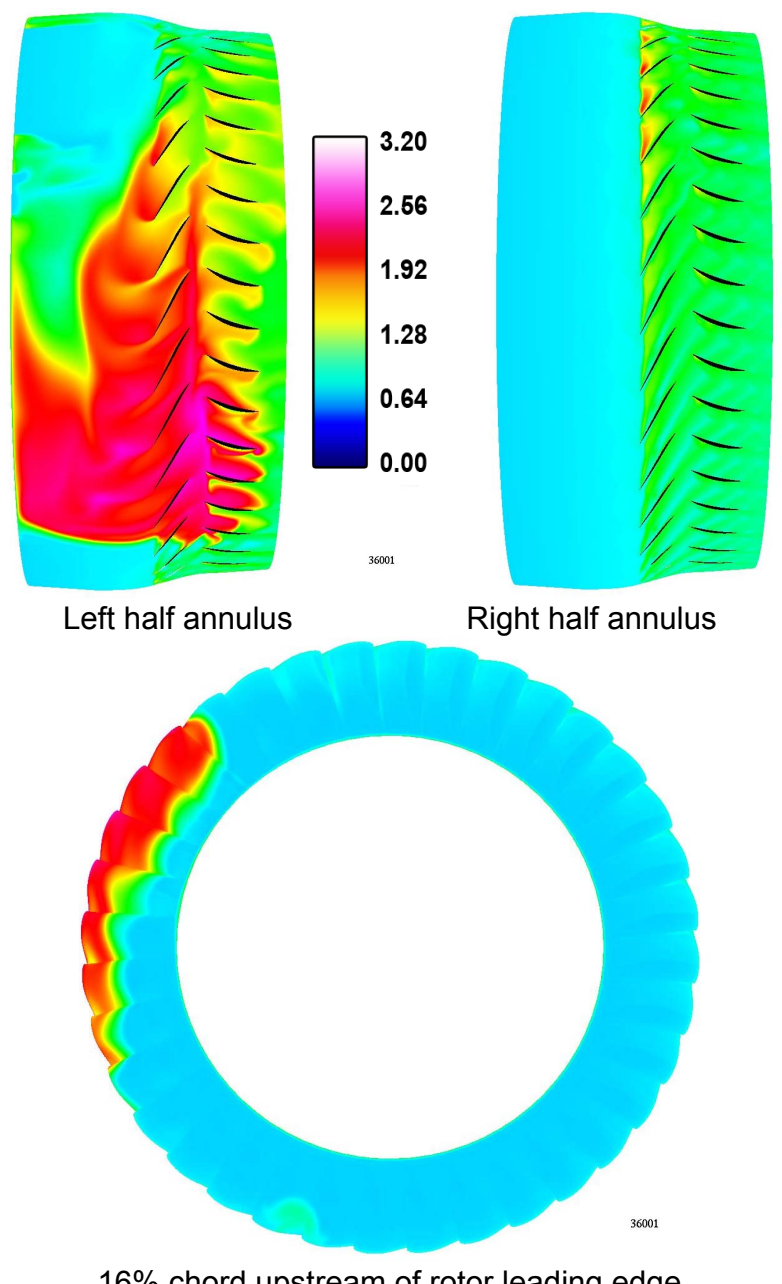

$16 \%$ chord upstream of rotor leading edge

Figure 9.-Entropy of Stage 35 during stall inception process, $\mathrm{t}=10 \mathrm{~T}$.

The three curves correspond to different phases at throttle setting $\mathrm{D}$ and $\mathrm{E}$ during the transition from stable operation to stall (fig. 10). Phase 1 is the last stable point before stall, which will be used as the baseline for comparison. Phases 2, 3 are the same throttle setting E, but at two different instants: one before stall (time E1), the other at the beginning of stall (time E2). Spatial FFTs of the pressure profile are shown in figure 12. The most dominant harmonic is the $36^{\text {th }}$ mode (its magnitude is at least one order of magnitude larger than others), which corresponds to the number of rotor blades. This disturbance is caused by the periodic flow features between blades and thus has the length scale associated with the rotor blade pitch. Not shown here is the strength of the $46^{\text {th }}$ mode, which is negligible. This indicates the influence of the stator on the potential field at rotor leading edge can be ignored. Therefore we will focus the study only on the rotor.

Modal disturbances, if any, should exist in the low harmonics with a longer length scale that is on the order of the rotor circumference. At phase 1 (D), only the $36^{\text {th }}$ mode prevails. This indicates that when away from stall, the only disturbance 


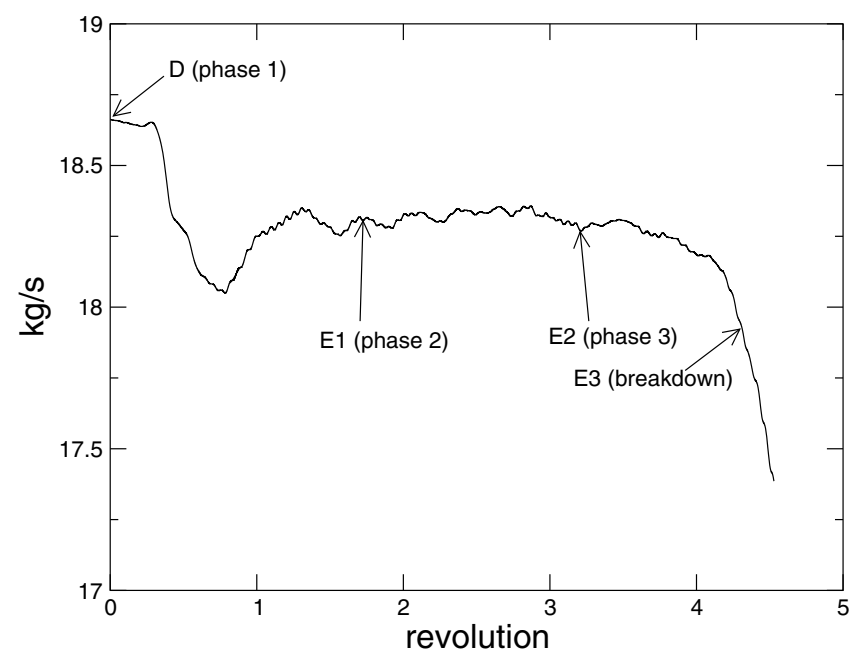

Figure 10.-Mass flow history at throttle setting $\mathrm{E}$.

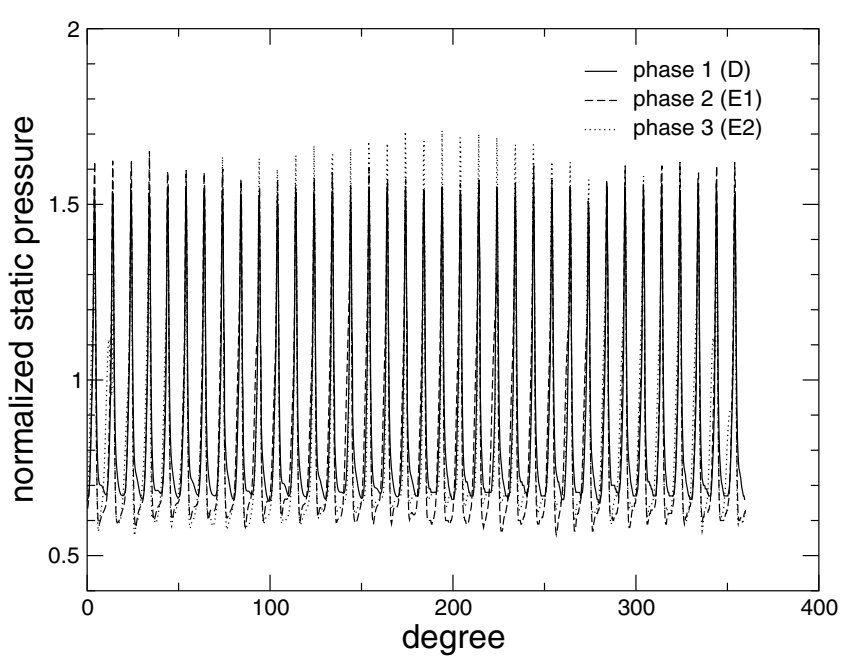

Figure 11.-Instantaneous pressure profile at rotor tip.

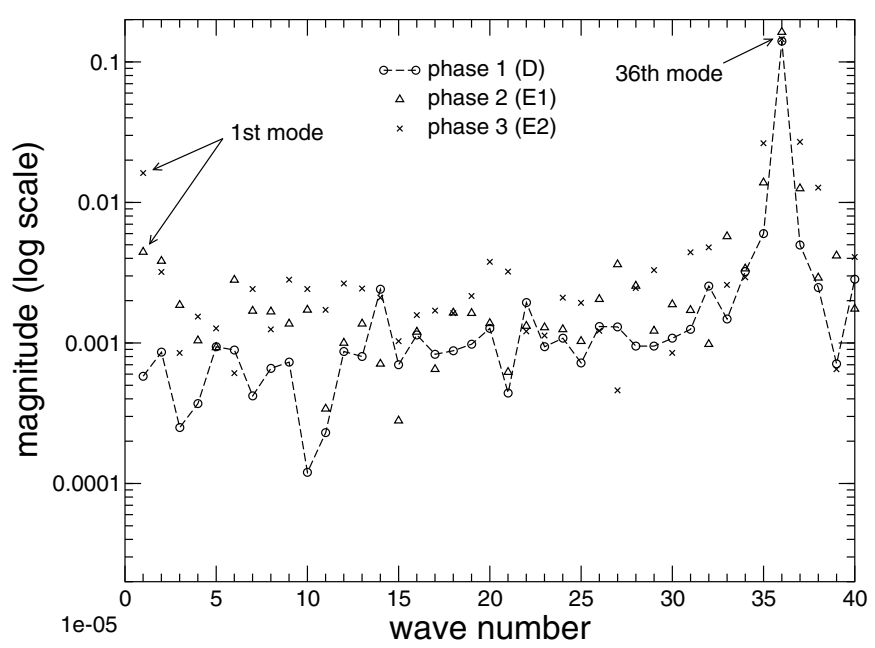

Figure 12._FFT of figure 11. to the otherwise uniform annulus flow is that from the periodic rotor passing and there is no modal activity. At phase 2 (time E1), the early phase of the rotating stall, there exists an identifiable $1^{\text {st }}$ mode along with the $36^{\text {th }}$ mode. There are also weaker but identifiable modes between the $1^{\text {st }}$ and the $36^{\text {th }}$ modes. As the simulation proceeds, bringing the compressor even closer to stall at phase 3 (time E2), the magnitude of the $1^{\text {st }}$ mode increases even more. The magnitudes of the modes in between remain relatively the same as those in the previous two phases, but fluctuate over the spectrum. The only mode that grows persistently during the pre-stall phase is the $1^{\text {st }}$ mode. This disturbance rotates at $100 \%$ rotor speed. This observation is the same as that of throttle setting F, where the speed of rotating mode is indicated in the pressure history of figure 7. This finding is similar to the experiment (see fig. 2) in that the less than one rotor circumference disturbance, which sits on top of the surge mode (not modeled in this simulation), starts to rotate at $80 \%$ rotor speed right before stall. It suggests perhaps that the simulation is adequately modeling the less than one rotor circumference modal disturbance before the compressor enters rotating stall.

A possible explanation of the origin of the $1^{\text {st }}$ mode can be derived from the following observations: 1) while the grid in our simulation does not include the complete ducting system, it does include the limited ducting that contains the rotor and the stator, 2) the speed of the rotating mode is $100 \%$ rotor speed; in another words, the $1^{\text {st }}$ mode is fixed to the rotor. This makes it likely that the disturbance is associated with the rotor. The two observations suggest that the $1^{\text {st }}$ mode may originate from a compound effect of the rotor blades and the limited volume effect present in the ducting of the current grid.

\section{Development of Mode and Spike}

To better understand the development of the $1^{\text {st }}$ mode and the spike disturbance, we focus on the evolution of the flow during the transient right before stall. Since stall is likely to be associated with the reverse flow (negative axial flow) we will monitor the development of the negative axial velocity of the flow during the transition. Figure 13(a) to (c) illustrates the axial velocity of the stage at three radial cut-planes at the three time instants E1, E2, E3 during the transient. The three cutplanes are located at: 4 clearance heights $(4 \varepsilon)$ below casing (cut-plane 1), 1.5 clearance heights $((1.5 \varepsilon)$ 1.below casing (cut-planes 2), and 0.5 clearance heights $(0.5 \varepsilon)$ below casing (cut-plane 3). Figure 13(d) illustrates the front views of cutplane 3 at the three time instants. The contours of the axial velocity have been truncated so that only the negative velocity has a color. All positive velocities are colored white.

At time E1, figure 13(a), about 2.5 revolutions before breakdown, the reverse flow is seen in all rotor passages with a radial coverage of at least 4 clearance heights below the casing, as indicated by the reverse flow being visible on all cut-planes. The rotor reverse flow is formed by the tip clearance vortex flow, which will be explained in detail later. The boundary and magnitude of the reverse flow region depicts the 


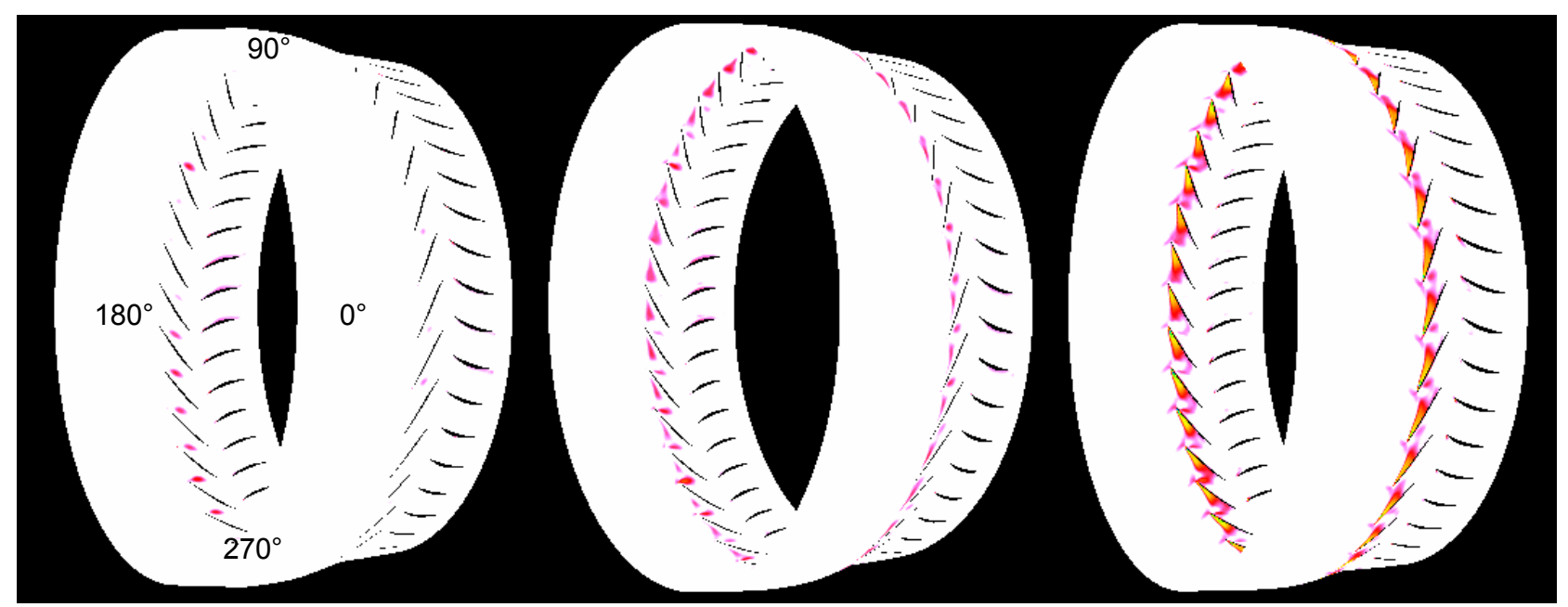

(a) Time E1 (2.5 T before rotating stall)

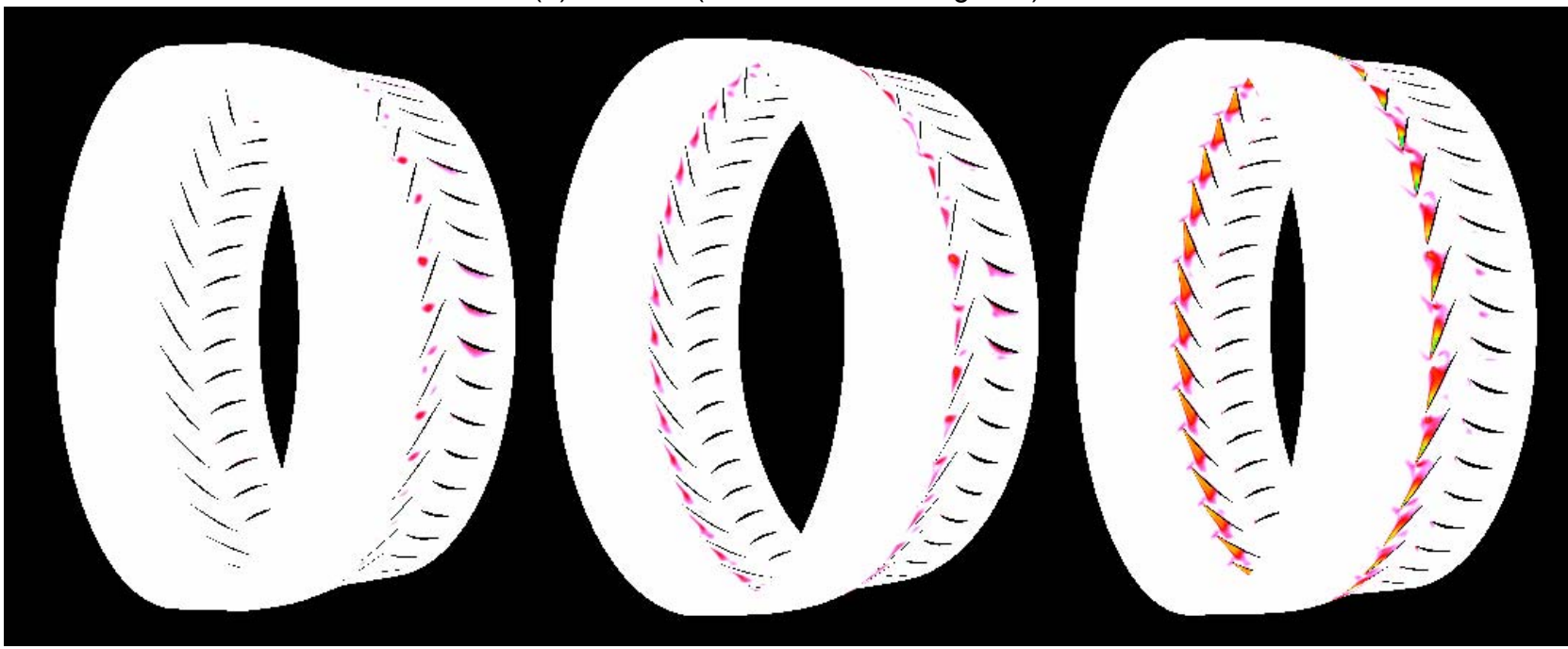

(b) Time E2 (beginning of rotating stall)

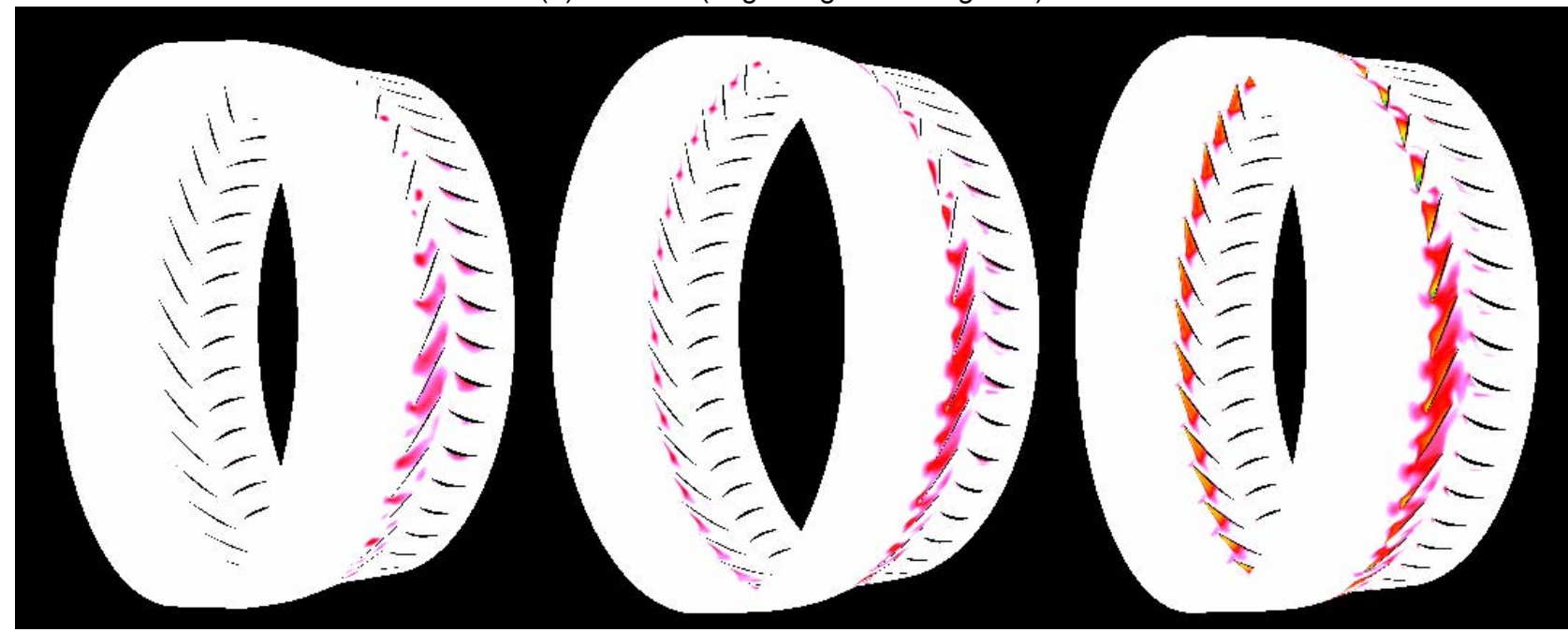

Cut-plane $1(4 \varepsilon)$

(c) Time E3 (during rotating stall) Cut-plane $2(1.5 \varepsilon)$

Cut-plane $3(0.5 \varepsilon)$

Figure 13.-(a), (b), and (c). Negative axial velocity at 3 cut-planes, 3 time instants. 


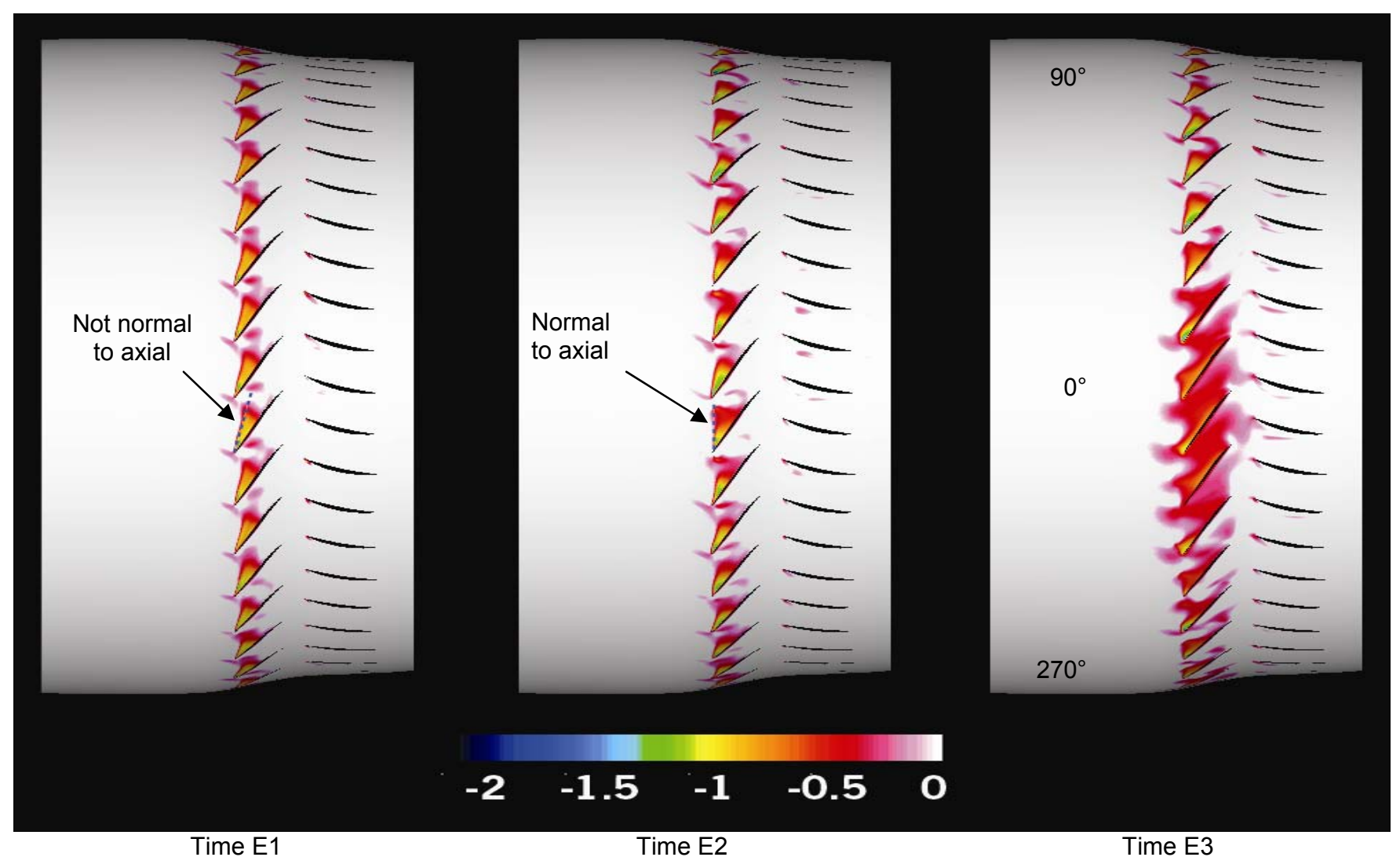

Figure 13.-Concluded. (d) Front views of cut-plane $3(0.5 \varepsilon)$ at three time instants, negative axial velocity.

boundary and the strength of the tip vortex. The patterns of the reverse flow are not the same in every passage, with the reverse flow zone larger on the back side of the view $\left(210^{\circ}\right)$. This can be readily seen on cut-planes 1 and 2 . The overall shape of rotor reverse flow corresponds well with the harmonics of figure 12 in that the $1^{\text {st }}$ mode co-exists with the $36^{\text {th }}$ mode. The speed of the $1^{\text {st }}$ mode is the same as the $36^{\text {th }}$ mode, both rotate at the rotor speed. The flow at this phase has already shown the instability.

At time E2, by comparing the front view of cut-plane 3 at time E1 and E2 (figure 13(d)), we see the front boundary of the reverse flow moves forward and becomes perpendicular to the axial direction. The magnitude of the negative velocity at time E2 is also higher than that at time E1 as is shown by more green spots at time E2. This is consistent with the shortlength stall inception mechanism described by Hoying et al. that spike stall initiates when the tip clearance vortex trajectories align perpendicularly to the axial direction. The larger reverse flow zone now rotates to the front side of the view $\left(0^{\circ}\right)$, figure 13(b), better seen on cut-planes 1 and 2 . Also seen on the two cut-planes is the appearance of reverse flow in the stator. Different from the reverse flow in the rotor, which is caused by tip clearance vortex, the stator reverse flow is caused by suction surface flow separation. An animation of the time-varying solution (not shown here) shows that the stator separation zones fluctuate in size as the rotor passes by, but otherwise stay in the stator blades where they originated. The stator separation zones do not appear to rotate at this time. A similar observation was also noted by Davis and Yao (2006).

At time E3, 1.1 revolutions after time E2, the flow formally enters the rotating stall. A zone of extended reverse flow covering five rotor passages can now be seen in the front view of cut-plane $3\left(330^{\circ}\right)$ in figure $13(\mathrm{c})$ and (d). This zone sits in the middle of the less extensive reverse flow characterized by the green colored tip clearance flow on cut-plane 3. This less extensive reverse flow correlates with the $1^{\text {st }}$ mode. The 5passage reverse flow zone initiates a spike-like disturbance on top of the $1^{\text {st }}$ mode and finally leads to the rotating stall.

Further analysis of the simulation also indicates the correlation between the $1^{\text {st }}$ mode disturbance of axial momentum and the appearance of spike. The circumferential profile of the axial momentum near the rotor tip leading edge is low-passfiltered to remove high-frequency noise so only the $1^{\text {st }}$ mode stays. Figure 14 shows the results at time E1, E2, and E3. The magnitude of the $1^{\text {st }}$ mode disturbance grows from E1 to E3 as it rotates around the annulus. The locations of the trough of the waves (marked in figure 14) are where the flow has the lowest axial momentum. These locations match the regions of the larger reverse flows in all three cut-planes mentioned 


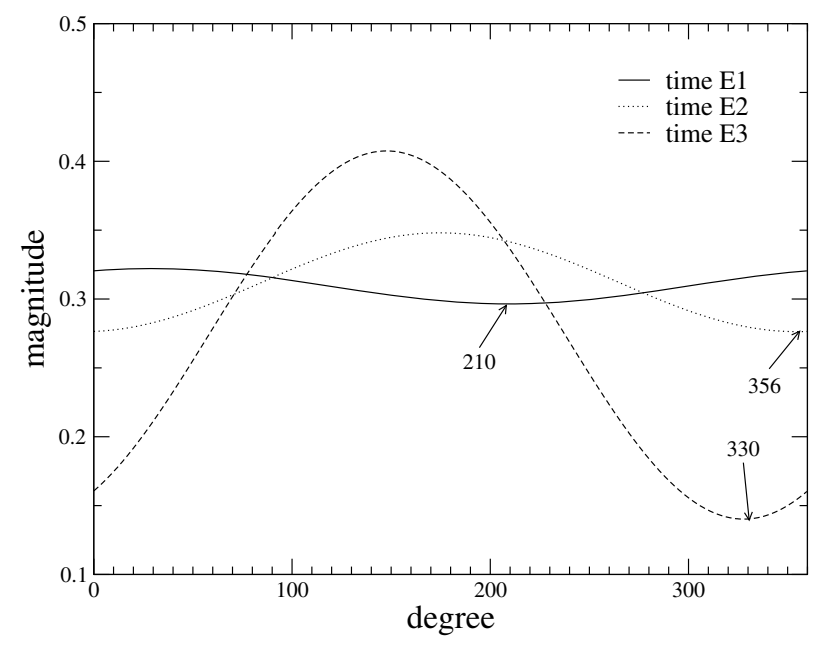

Figure 14.-First mode disturbances of axial momentum at rotor tip.

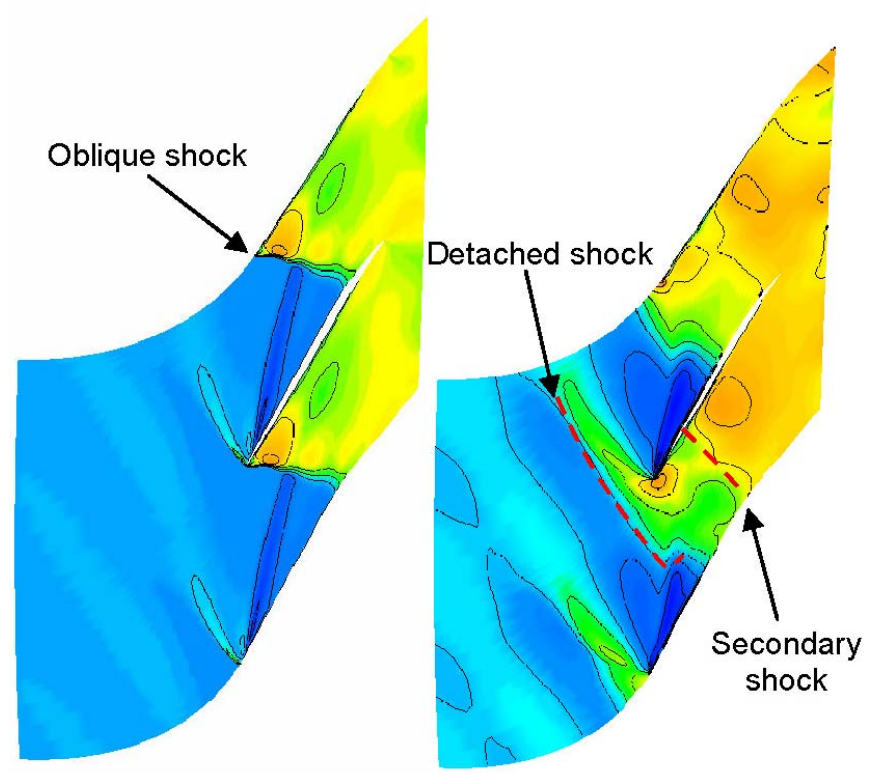

(a) Stable condition

(b) Near stall condition (time E1)

Figure 15.-Pressure contour near casing.

previously. This is consistent with the observation of Day (1993) that spikes can grow out of the trough of the axial velocity modal waves if critical incidence is reached.

As we pointed out before it is difficult to discern the actual transition from the rotating modal wave to the start of the rotating stall in figure 2 . The simulation provides the details to complement the experiment. It is demonstrated here that a spike of 5 passages long does occur. It evolves smoothly out of the rotating mode and eventually leads to the breakdown (rotating stall).

\section{Interaction of Shock and Tip Clearance Flow}

Interaction between the tip clearance flow and shock in transonic compressor has been cited as one of the initiators of spike disturbance. As noted by Day (1993), short-length spikes can be viewed as embryonic stall cells with flow breakdown in local regions; it is a 3D phenomenon. Computational simulations using a single blade passage to study the effect of the tip clearance flow on the onset of stall were reported by Adamczyk et al. (1993). One generally agreed conclusion is that the tip clearance vortex moves forward from stable to stall condition. Using vortex kinematics arguments, Hoying et al. (1999) developed a criterion for stall inception when the trajectory of the tip clearance vortex becomes perpendicular to the axial direction. Vo et al. (2005) also demonstrated that stall inception is most likely accompanied by the forward spillage of tip clearance vortex. One might ask: How does the shock interact with the tip clearance flow? Does the shock directly cause flow separation that may contribute to the stall inception?

To answer these questions, we take a closer look at the flow within the rotor passage. A comparison of pressure contours near the casing between the stable and near-stall (time E1) condition is made in figure 15 . In the stable condition, the pressure fields in the two passages shown are almost identical. There exists a distinguishable attached oblique passage shock, which originates from the leading edge of the rotor blade and extends across the passage to $80 \%$ chord on the suction surface of the adjacent blade. At time E1, the pressure fields between passages are no longer identical. Even though the flow structure is not identical among passages there is still similarity between them before the flow breakdown. We will discuss the common features that are generic for all passages before stall. Examining the pressure field at time E1, we see the single attached oblique shock now changes to a more complicated dual-shock system: a strong detached shock followed by a weaker secondary shock. The strong detached shock, together with the stagnant flow around the leading edge, creates a high pressure region near the leading edge of the pressure surface. The pressure outside this area is relatively low until aft of the secondary shock where the pressure level once again rises but now fills uniformly between the blades.

Streamlines forming the tip clearance vortex for both stable and near-stall (time E1) conditions are shown in figure 16. The pressure contour near the casing is overlaid in the background to help the discussion. First take a look at the stable condition. Only the forward $15 \%$ portion of the tip clearance flow emerges to form the core of the tip clearance vortex. The trajectory of the tip clearance vortex is not perpendicular to the axial direction. The oblique shock intersecting the vortex only slightly alters the shape of the vortex. The vortex moves away from pressure surface of the adjacent blade without impinging it. 


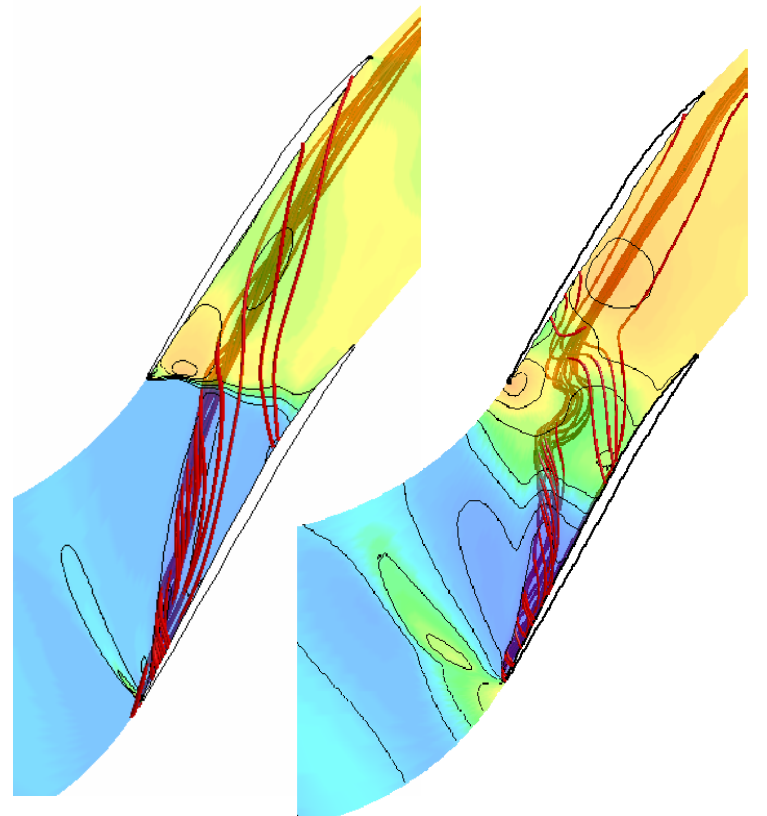

(a) Stable condition

(b) Near stall condition (time E1)

Figure 16.-Stream lines forming the tip clearance vortex.

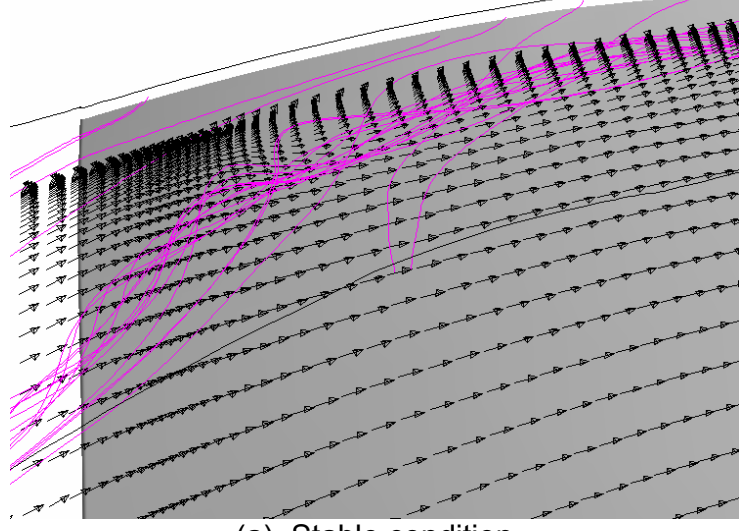

(a) Stable condition

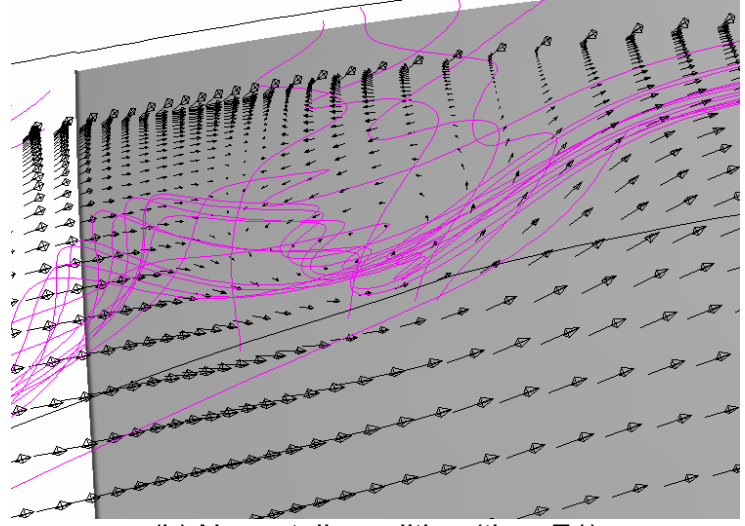

(b) Near stall condition (time E1)

Figure 17.--Velocity vector on a meridional plane $30 \%$ pitch off pressure surface.
At the near-stall condition (time E1), figure 16(b), the core vortex, again formed by the forward $15 \%$ of the tip clearance flow, now moves forward. The center portion of the vortex trajectory becomes perpendicular to the axial direction. This trend follows well with the stall inception criterion of Hoying et al., (1998). However, the shape of the vortex trajectory is first pushed backward by the high pressure near the pressure surface leading edge and then forward by the high pressure behind the secondary shock as it proceeds downstream. This distortion of the vortex trajectory is caused by the dual-shock system. The criterion of Hoying, developed for low-speed machines, still holds for areas not affected by the dual-shock. It is unclear whether or not the distorted vortex can accelerate the flow breakdown, but it is clear that the distortion occurs as the flow is close to stall with the existence of the dual-shock.

Flow is likely to separate due to the shock-boundary layer interaction, in which the low momentum flow in the boundary layer is subjected to the sudden pressure rise across the shock. Thus, it is of interest to examine whether shock-induced flow separations occur in the simulation. There are two possible locations for flow separation in the rotor passage: one is on the suction surface and the other is on the casing surface. By examining the streamlines in figure 16 , we rule out the suction surface separation. To search for the casing separation, the velocity vector in the meridional view is examined. Figure 17 (a) shows such a plane $30 \%$ pitch off the pressure surface. There is no observable reverse flow in this view. This indicates that the vortex moves straight downstream and that the flow remains attached to the casing. At time E1, the reverse flow associated with the distorted vortex can be seen in figure $17(\mathrm{~b})$. The velocity vector shows that the flow reversal occurs beneath the casing and is caused by the organized spiraling fluids of the distorted vortex. There is no indication of casing separation at this instant. The cross-section of the vortex, however, is larger than the stable condition. This also shows that the negative axial velocity of the rotor flow shown in figure 13 is caused by the spiraling fluids of the tip clearance vortex and has no association with casing or blade separation. With the above observations, we conclude there is no shock-induced separation in this during the stall inception.

As the compressor proceeds more into stall between times $\mathrm{E} 2$ and $\mathrm{E} 3$, the flow is breaking down, i.e., the mass flow rate through the compressor is declining. The reverse flow in a few passages combines to form the large blockage as shown in figure 13(b) and (c), which in turn expels flow to adjacent blades. The blockage creates the spike-type disturbance over a few passages. The expelled flow entering the adjacent blade passages brings in extra axial momentum to the casing areas of these passages. The additional axial momentum behaves like tip injection, which reduces rotor incidence levels, relative to time E1. The vortex shape and shock structure of two passages at time E2 are compared in figure 18. Figure 18(a) is a passage where the spike occurs. The shape of the vortex trajectory and shock structure is similar to those at time E1, figure 16(b), only that the vortex continues to grow and the high pressure behind the detached shock pushes the vortex 
backward so the trajectory moves away from being normal to the axial direction. Spillage of tip clearance forward of the leading edge can be seen in figure 19(a), where it is colored by the pink stream-lines. In the passage where the flow condition improved, as shown in figure 18(b), the dual-shock system returns to a single-shock and the vortex trajectory is not distorted. There is no spillage of the tip clearance flow forward of the leading edge, figure 19(b).

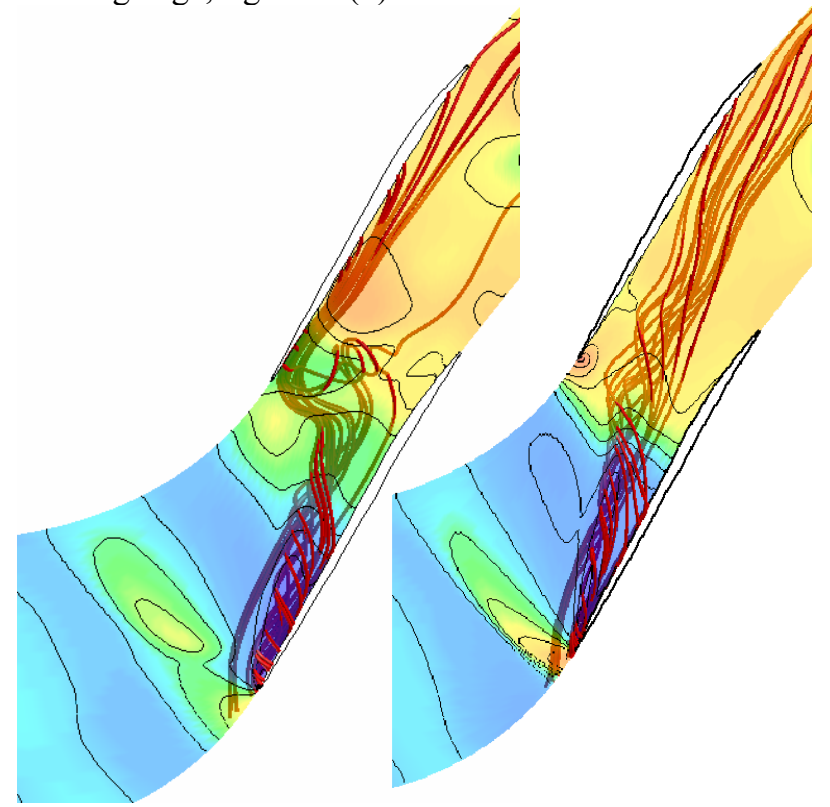

(a) Deteriorating passage

(b) Improving passage

Figure 18.-Tip clearance vortex at time E2.

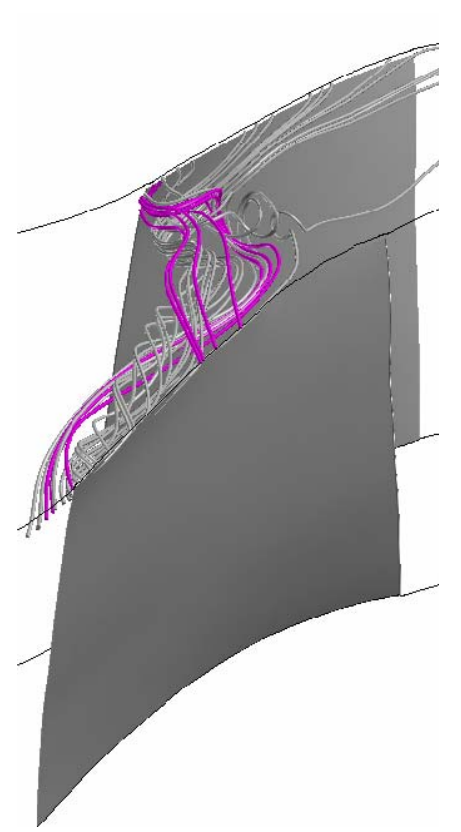

(a) Spillage in deteriorating passage

(b) No spillage in improving passage

Figure 19.-Tip clearance flow showing spillage over rotor leading edge at time E2.

\section{Simulation Summary}

(1) The simulation results of the high speed axial compressor Stage 35 provide evidence that the current numerical procedure may be adequate for predicting the onset of flow instabilities and their subsequent growth into a fully developed rotating stall. The simulation results clearly show a fullannulus $1^{\text {st }}$ mode disturbance starting to travel at $100 \%$ rotor speed at the peak of the pressure rise transitions to a spike disturbance that traveling at $84 \%$ rotor speed. This spike disturbance then splits into multiple stall cells while their speeds reduce. Finally the multiple stall cells coalesce into a large single stall cell that rotates at $43 \%$ of rotor speed when fully developed. This simulation models the natural growth of the stall process without the use of an artificial inlet distortion.

(2) As the simulation is throttled to stall, small amplitude long-length waves of $1^{\text {st }}$ mode and high-order modes between the $1^{\text {st }}$ and the $36^{\text {th }}$ can be discerned. The magnitudes of the high-order modes fluctuate, but do not grow much during the transition to stall. The $1^{\text {st }}$ mode wave, however, persistently grows before breakdown. A short-length disturbance covering five rotor passages bursts into a spike-like disturbance during the breakdown. This spike disturbance then grows into a rotating stall.

(3) The computed $1^{\text {st }}$ mode disturbance has a length scale closely resembling the less than one rotor circumference disturbance prior to stall in the experiment. The computed speed of the $1^{\text {st }}$ mode disturbance ( $100 \%$ rotor speed) is also similar to the measured speed ( $80 \%$ rotor speed) of the $1^{\text {st }}$ mode disturbance from the experiment, estimated from the results of figure 2. The difference is within the resolution of the picture quality of the published data.

(4) The $1^{\text {st }}$ mode of the axial momentum correlates well with the appearance of the growing reverse flow. The trough of the axial momentum matches the region of the larger reverse flow that leads to the birth of the initial spike.

(5) The interaction of the shock and tip clearance vortex is examined. As the compressor approaches stall the trajectory of the tip clearance vortex moves forward to become perpendicular to the axial direction. The shock system, in the meantime, also moves forward, changing from an attached oblique single-shock to a dual-shock. The pressure field of the dual-shock system distorts the trajectory of the tip clearance vortex, creating a large reverse flow region in the distorted vortex. The reverse flow in the rotor is the outward tip clearance vortex as no shock-induced casing- or blade-separation is found.

(6) During the flow breakdown, spillage of the tip clearance flow forward of the rotor leading edge is found in several passages, where the flow condition is deteriorating. A large blockage region is formed in the deteriorating passages; this in turn impels flow to enter into adjacent passages. The influx of fluid momentum in the adjacent passages improves the flow condition there. 


\section{Conclusions}

The TURBO code has been applied to the 3D full-annulus simulation of a transonic compressor stage NASA Stage 35 to investigate the flow evolution prior to stall. This simulation does not include the system volume, and therefore cannot model the surge mode oscillation that arises from the test facility ducting system. With the surge mode removed, the stalling flow first takes the form of a rotating long-length (modal) disturbance; it then changes into a spike. The spike seems to grow out of the long-length disturbance and eventually leads to stall. The spike emerges when the tip clearance vortex becomes perpendicular to the axial direction and in some passages, with forward spillage. The passage shock changes from single-shock to dual-shock when approaching to stall. The dual-shock distorts the trajectory of the vortex but doesn't cause flow separation that directly contribute to the stall. The simulation correlates well with the experiment data excluding the surge mode. The computational resources involved in conducting such a simulation are prohibitively large at the time and are not suitable for routine executions. While this is certainly an issue, the key point is that the simulations of this type generate qualitatively and quantitatively accurate flow field data which can support our understanding and inferences of the unsteady compressor flow field, including support and interpretation of experimental work.

\section{References}

Adamczyk, J.J., Celestina, M.L., and Greitzer, E.M.: 1993, 'The Role of Tip Clearance in High-Speed Fan Stall," ASME Journal of Turbomachinery, vol. 115 , pp. 28-38.

Bright, M.M., Qammar, H.K., and Wang, L.: 1999, "Investigation of Pre-Stall Mode and Pip Inception in High-Speed compressors Through the Use of Correlation Integral," ASME Journal of Turbomachinery, vol. 121, pp. 743-750.

Camp, T.R. and Day, I.J.: 1998, "Study of Spike and Modal Stall Phenomenon in a Low-Speed Axial Compressor," ASME Journal of Turbomachinery, vol. 120, no. 3. pp. 393-401

Chen, J. P., and David L. Whitfield: 1993, "Navier-Stokes Calculations for the Unsteady Flowfield of Turbomachinery," AIAA paper AIAA-93-0676.

Chen, J.P. and Barter, J.: "Comparison of Time-Accurate Calculations for the Unsteady Interaction in Turbomachinery Stage," AIAA paper AIAA-98-3293.

Chen, J.P. and Briley, W.R.: 2001, "A Parallel Flow Solver for Unsteady Multiple Blade Row Turbomachinery Simulations," ASME paper GT-2001-348.

Chen, J.P., Webster, R.S., Hathaway, M.D., Herrick, G.P., and Skoch, G.J.: 2006, "Numerical Simulation of Stall and Stall Control in Axial and Radial Compressors," AIAA paper AIAA-2006418.

Chima, R.V.: 1998, "Calculation of Tip Clearance Effects in a Transonic Compressor Rotor," ASME Journal of Turbomachinery, vol. 120, pp. 131-140.

Cumpsty, N.A.: 2004, "Compressor Aerodynamics," Krieger Publishing Co.
Davis, R.L. and Yao, J.: 2006, "Prediction of Compressor Stage Performance from Choke through Stall," AIAA Journal of Propulsion and Power, vol. 22, no. 3, pp. 550-557.

Day, I.J.: 1993, "Stall Inception in Axial Flow Compressors," ASME Journal of Turbomachinery, vol. 115, pp. 1-9.

Garnier, V.H., Epstein, A.H., and Greitzer: E.M.: 1991, "Rotating Waves as a Stall Inception Indication in Axial Compressors," ASME Journal of Turbomachinery, vol. 113, pp. 290-302.

Gong, Y., Tan, C.S., Gordon, K.A., and Greitzer, E.M.: 1999, "A Computational Model for Short Wavelength Stall Inception and Development in Multistage Compressors," ASME Journal of Turbomachinery, vol. 121, pp. 726-734.

Hah, C., Bergner, J., and Schiffer, H.-P.: 2006, "Short Length-Scale Rotating Stall Inception in a Transonic Axial CompressorCriteria and Mechanisms," ASME paper GT2006-90045.

Hathaway, M.D., Chen, J., Webster, R., Herrick, G.P.: 2004, “Time Accurate Unsteady Simulations of the Stall Inception Process in the Compression System of a U.S. Army Helicopter Gas Turbine Engine," 2004 DoD High Performance Computing Modernization Program User's Group Conference, Williamsburg, VA., June 7-10, 2004.

He, L.: 1997, "Computational Study of rotating-Stall Inception in Axial Compressors," Journal of Propulsion and Power, vol. 13, no.1, pp. 31-38.

Hoying, D.A., Tan, C.S., Vo, H.D., and Greitzer, E.M.: 1998, "Role of Blade Passage Flow Structures in Axial Compressor Rotating Stall Inception," ASME Journal of Turbomachinery, vol. 121, pp. 735-742.

Kirtley, K.R., Beach, T.A., and Adamczyk, J.J.: 1990, "Numerical Analysis of Secondary Flow in a Two-Stage Turbine," AIAA paper AIAA-90-2356.

Reid, L., and Moore, R.D.: 1978, "Performance of Single-Stage Axial-Flow Transonic Compressor with Rotor and Stator Aspect Ratios of 1.19 and 1.26, Respectively, and With Design Pressure Ratio of 1.82," NASA Technical Paper TP-1338.

Saxer-Felici, H.M., Saxer, A.P., Inderbitzin, A., and Gyarmathy, G.: 2000, "Numerical and Experimental Study of Rotating Stall in an Axial Compressor Stage," AIAA Journal, vol. 38, no. 7.

Spakovszky, Z.S., Weigl, H.J., Paduano, J.J., van Schalkwyk, C.M., Suder, K.L., and Bright, M.M.: 1999, "Rotating Stall Control in a High-Speed Stage with Inlet Distortion: Part I-Radial Distortion," ASME Journal of Turbomachinery, vol. 121, pp.510-516.

Suder, K.L., Hathaway, M.D., Thorp, S.A., Strazisar, A.J., and Bright, M.M.: 2001, "Compressor Stability Enhancement Using Discrete Tip Injection," ASME Journal of Turbomachinery, vol. 123, pp. 14-23.

Van Zante, D.E., Strazisar, A.J., Wood, J.R., Hathaway, M.D., and Okiishi, T.H.: 2000, "Recommendations for Achieving Accurate Numerical Simulation of Tip Clearance Flows in Transonic Compressor Rotors," ASME Journal of Turbomachinery, vol. 122, pp. 733-742.

Vo, H.D., Tan, C.S., and Greitzer, E.M.: 2005, “Criteria for Spike Initiated Rotating Stall,” ASME paper GT2005-68374.

Weigl, H.J., Paduano, J.D., Frechette, L.G., Epstein, A.H., Greitzer, E.M., Bright, M.M., and Strazisar, A.J.: 1998, “Active Stabilization of Rotating Stall and Surge in a Transonic Single Stage Axial Compressor," ASME Journal of Turbomachinery, vol. 120, no. 4, pp. 625-636. 


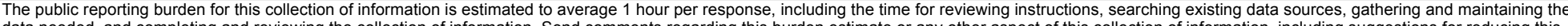

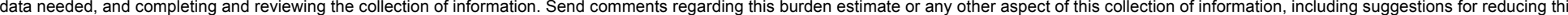

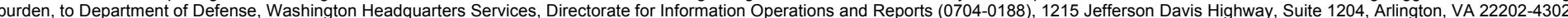

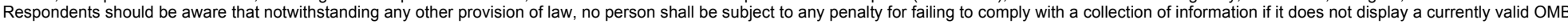
control number.

PLEASE DO NOT RETURN YOUR FORM TO THE ABOVE ADDRESS.

\section{REPORT DATE (DD-MM-YYYY) \\ 2. REPORT TYPE \\ 3. DATES COVERED (From - To)}

01-06-2008

Technical Memorandum

\section{TITLE AND SUBTITLE}

Pre-Stall Behavior of a Transonic Axial Compressor Stage Via Time-Accurate Numerical

Simulation

\section{5a. CONTRACT NUMBER}

5b. GRANT NUMBER

5c. PROGRAM ELEMENT NUMBER

6. AUTHOR(S)

Chen, Jen-Ping; Hathaway, Michael, D.; Herrick, Gregory, P.

\section{5d. PROJECT NUMBER}

5e. TASK NUMBER

5f. WORK UNIT NUMBER

WBS 877868.02.07.03.01.02

\section{PERFORMING ORGANIZATION}

REPORT NUMBER

E-16405

National Aeronautics and Space Administration

John H. Glenn Research Center at Lewis Field

Cleveland, Ohio 44135-3191

\section{SPONSORING/MONITORING AGENCY NAME(S) AND ADDRESS(ES)}

National Aeronautics and Space Administration

Washington, DC 20546-0001

and

U.S. Army Research Laboratory

Adelphi, Maryland 20783-1145

\section{DISTRIBUTION/AVAILABILITY STATEMENT}

Unclassified-Unlimited

Subject Category: 07

Available electronically at http://gltrs.grc.nasa.gov

This publication is available from the NASA Center for AeroSpace Information, 301-621-0390

\section{SUPPLEMENTARY NOTES}

\section{ABSTRACT}

CFD calculations using high-performance parallel computing were conducted to simulate the pre-stall flow of a transonic compressor stage, NASA compressor Stage 35. The simulations were run with a full-annulus grid that models the $3 \mathrm{D}$, viscous, unsteady blade row interaction without the need for an artificial inlet distortion to induce stall. The simulation demonstrates the development of the rotating stall from the growth of instabilities. Pressure-rise performance and pressure traces are compared with published experimental data before the study of flow evolution prior to the rotating stall. Spatial FFT analysis of the flow indicates a rotating long-length disturbance of one rotor circumference, which is followed by a spike-type breakdown. The analysis also links the long-length wave disturbance with the initiation of the spike inception. The spike instabilities occur when the trajectory of the tip clearance flow becomes perpendicular to the axial direction. When approaching stall, the passage shock changes from a single oblique shock to a dual-shock, which distorts the perpendicular trajectory of the tip clearance vortex but shows no evidence of flow separation that may contribute to stall.

\section{SUBJECT TERMS}

Transonic compressor; Rotating stall; Simulations

\section{SECURITY CLASSIFICATION OF}

a. REPORT

$\mathrm{U}$ $\mathrm{U}$

\section{LIMITATION OF} ABSTRACT

UU

18. NUMBER
OF
PAGES
20

10. SPONSORING/MONITORS ACRONYM(S)

NASA; ARL

11. SPONSORING/MONITORING REPORT NUMBER

NASA/TM-2008-215163; ARL-TR-4085

\section{PAGE}

$\mathrm{U}$ 19a. NAME OF RESPONSIBLE PERSON

STI Help Desk (email:help@sti.nasa.gov)

19b. TELEPHONE NUMBER (include area code) 301-621-0390 

